Louisiana State University

LSU Digital Commons

An examination of challenging behaviors in autistic disorder versus pervasive developmental disorder not otherwise specified: significant differences and gender effects

\author{
Alison M. Kozlowski \\ Louisiana State University and Agricultural and Mechanical College
}

Follow this and additional works at: https://digitalcommons.Isu.edu/gradschool_theses

Part of the Psychology Commons

\footnotetext{
Recommended Citation

Kozlowski, Alison M., "An examination of challenging behaviors in autistic disorder versus pervasive developmental disorder not otherwise specified: significant differences and gender effects" (2010). LSU Master's Theses. 837.

https://digitalcommons.Isu.edu/gradschool_theses/837
}

This Thesis is brought to you for free and open access by the Graduate School at LSU Digital Commons. It has been accepted for inclusion in LSU Master's Theses by an authorized graduate school editor of LSU Digital Commons. For more information, please contact gradetd@lsu.edu. 


\title{
AN EXAMINATION OF CHALLENGING BEHAVIORS IN AUTISTIC DISORDER VERSUS PERVASIVE DEVELOPMENTAL DISORDER NOT OTHERWISE SPECIFIED: SIGNIFICANT DIFFERENCES AND GENDER EFFECTS
}

\author{
A Thesis \\ Submitted to the Graduate Faculty of the \\ Louisiana State University and \\ Agricultural and Mechanical College \\ in partial fulfillment of the \\ requirements for the degree of \\ Master of Arts
}

In

The Department of Psychology

by

Alison M. Kozlowski

B.A., Boston University, 2006

August 2010 


\section{Table of Contents}

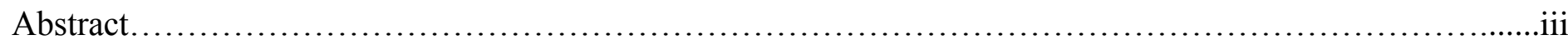

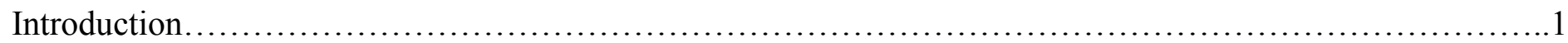

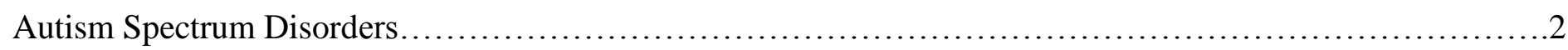

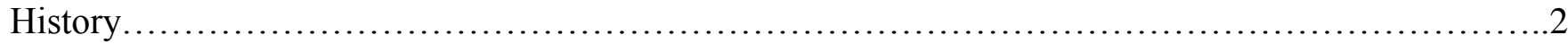

Differential Diagnosis....................................................................

Prevalence.......................................................................... 11

Challenging Behaviors and Autism Spectrum Disorders.............................................

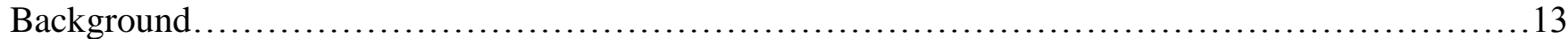

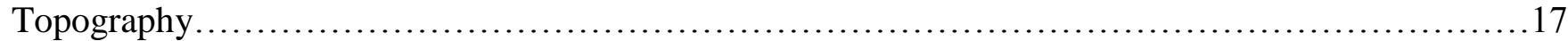

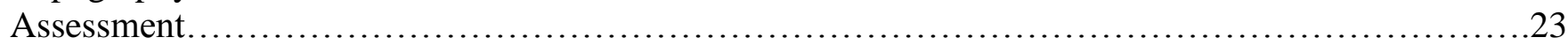

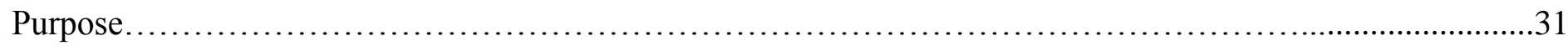

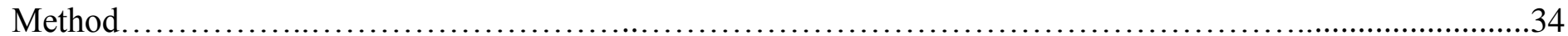

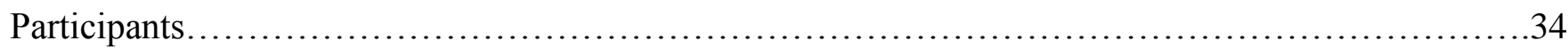

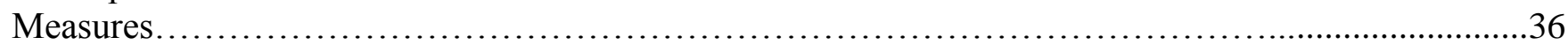

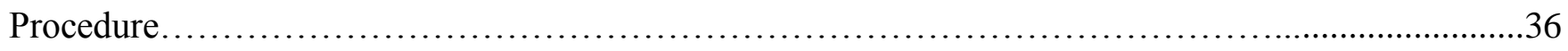

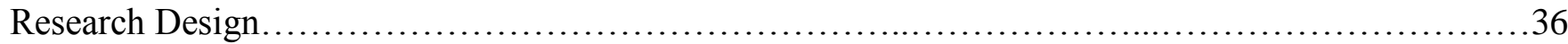

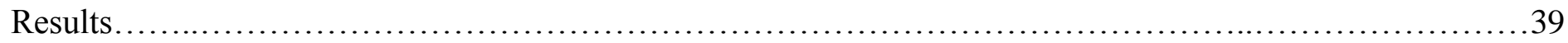

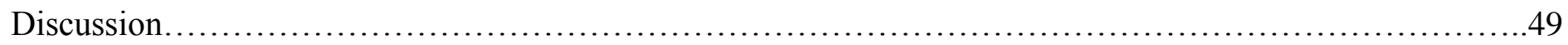

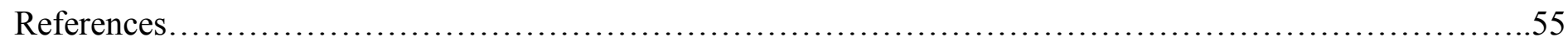

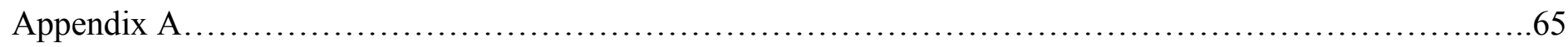

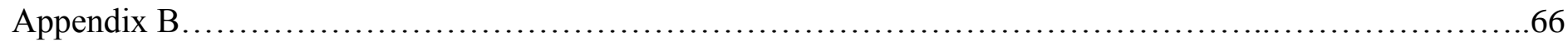

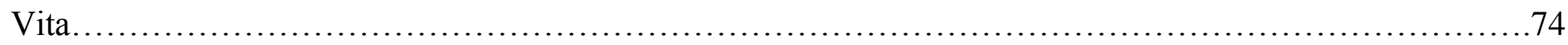




\begin{abstract}
Children with Autism Spectrum Disorders (ASDs) are well-known for engagement in challenging behaviors. Unfortunately, due to its absence as a criterion for diagnosis in the DSM-IV-TR, little attention has been paid to the endorsement rates of such behaviors. However, a recently developed measure to assist in the diagnosis of infants and toddlers with autism and PDD-NOS - the Baby and Infant Screen for Children with aUtIsm Traits (BISCUIT) - has included a section designated for just this reason. This study used the BISCUIT to assess for significant differences in the endorsement rates of challenging behaviors between infants and toddlers with autism versus PDD-NOS as well as for significant differences between genders. There were significant differences between the diagnostic groups in endorsement rates of challenging behaviors as a whole, as well as among many specific behavior items. No significant differences between genders in endorsement rates of challenging behaviors were found. The implications of these findings are discussed.
\end{abstract}




\section{Introduction}

Pervasive Developmental Disorders, more commonly referred to as Autism Spectrum Disorders (ASDs), are a set of five neurodevelopmental disorders typically diagnosed in the first few years of life that include Autistic Disorder (autism), Asperger's Disorder, Rett's Disorder, Childhood Disintegrative Disorder, and Pervasive Developmental Disorder Not Otherwise Specified (PDD-NOS) (American Psychiatric Association [APA], 2000). These disorders are characterized by varying degrees of deficiencies in social skills and communication as well as restricted interests, activities, and behaviors - handflapping, preoccupation with objects, rocking, etcetera. Additionally, though not considered to be a qualifying factor in diagnosis, challenging behaviors such as self-injury, aggression, and property destruction are found in the majority of ASD cases (Matson \& Nebel-Schwalm, 2007; Mudford et al., 2008). Due to such a high prevalence, a multitude of research has been conducted to assess and treat challenging behaviors. However, possibly due to their not being included in a diagnosis of ASD, the prevalence of challenging behaviors in infants and toddlers has been overlooked in regards to significant differences in endorsement rates between children diagnosed with autism and those with PDD-NOS. Furthermore, the effect of gender on the presence of challenging behaviors within these populations has rarely been addressed. However, such differences are suggested to occur within other populations and preliminary research suggests this may also be true in the ASD population.

Recently, the Baby and Infant Screen for Children with aUtIsm Traits (BISCUIT) has been constructed, which has a section specifically designed to assess the rates of challenging behaviors evinced within the ASD population (Matson, Wilkins, Sevin et al., 2009). The purpose of this study will aim to identify significant differences in endorsement rates of challenging behaviors in infants and toddlers with autism and PDD-NOS using this measure. Additionally, gender differences on problem behavior items will also be investigated. Prior to these studies, a brief description of ASDs will be presented along with current research in the area of challenging behaviors. 


\section{Autism Spectrum Disorders}

\section{History}

In 1943, in his now famous paper entitled 'Autistic Disturbances of Affective Contact,' Leo Kanner began to describe a previously unheard of disorder that has since credited him with the discovery of autism. This initial account began with only 11 children, the majority of which were boys, who exhibited peculiar behaviors that had not been previously noted to occur together as a syndrome - namely, the inability to relate themselves to others, deficits in communication, and the preservation of sameness. These behaviors were generally present early in life providing Kanner with the belief that the problems were innate. In fact, at the time, it was thought to be the earliest psychosis to occur (Eisenberg, 1956). Several papers followed this original publication, by Kanner and others, which further depicted the symptoms of what Kanner himself later termed "early infantile autism" (1944).

According to Kanner, the first of the three symptoms of early infantile autism was an inability of the child to relate himself to others, commonly described as an "extreme autistic aloneness" (Kanner, 1943, 1944). This difficulty was considered to be present very early in life and could perhaps even be the earliest sign noted, as a symptom of it could be observed at only a few months of age. Generally, an infant will display an anticipatory posture prior to being picked up followed by positioning adjustments to better accommodate the person holding him (Eveloff, 1960; Kanner, 1943, 1944). However, this was not the case with the children Kanner and others encountered. Instead, these children could be described as having severe deficits in socialization to the point of completely ignoring external persons and situations whenever possible. In some cases the extreme nature of this isolation was so profound that those involved questioned whether the child was in fact deaf (Eveloff, 1960; Kanner, 1943). Furthermore, the children preoccupied themselves with a fascination with objects that was clearly more prominent than any interest in social interaction (Kanner, 1943, 1944, 1971).

Secondly, Kanner (1943) noted severe impairments in communication. Many children were even found to be mute. While some children were able to develop speech, the types of speech they acquired were not sufficient to converse meaningfully with others. Those who did speak mostly did so by evincing either 
immediate or delayed echolalia. Words and phrases lacked contextual meaning as they were often quotations heard beforehand. In conjunction with this, pronominal reversal was prominent. The children would consistently reverse the pronouns "I" and "you" when speaking about themselves and others. This was done because the children fixated on repeating the pronouns as they had previously been heard including maintenance of the spoken intonation. For example, if a mother questioned, "Are you hungry?" the child would come to communicate his hunger by stating "You are hungry?" as opposed to "I am hungry." Overall, if the child does develop speech, he still shows a lack of purposeful communication, thorough understanding, and generalization skills.

The final major finding in those with early infantile autism was their insistence on the preservation of sameness (Kanner, 1943, 1951). If their environment or routine was changed, even if it was noted to be only temporary or a slight variation, the children would go to extreme lengths to demand the change be undone. Additionally, broken items and things that were perceived to be incomplete were often rejected. To these children, everything had its rightful place, time, and function. Tantrum behavior was often exhibited when any of these rules were broken (Kanner, 1951). Generally speaking, the children engaged in obsessive-compulsive behavior in attempts to preserve the sameness of their environment.

Though challenging behaviors were not considered to be a core feature of early infantile autism, they were present in several documented cases. The most common of these behaviors appears to be temper tantrums, which typically included noncompliance (Kanner, 1943, 1951, 1971). Tantrum behavior was often witnessed as a response to disruption of the preservation of sameness. Additionally, accounts included descriptions of physical aggression, self-injurious behavior, property destruction, and disrobing (Eveloff, 1960; Kanner, 1971). Estimated rates of the occurrences of challenging behaviors are difficult to conclude from the narratives given, but it is evident that challenging behaviors did present themselves relatively regularly.

Even though the majority of the early history of autism is attributed to Kanner who is the individual most commonly linked to its discovery, he was not the only one to study such a disorder. Hans Asperger, a doctoral student in Austria at the time, published his thesis in 1944 that described an almost identical disorder in 
four separate children (1991). However, since Asperger's work, “Autistic Psychopathy in Childhood,” was originally published in German and not translated into English by Uta Frith until 1991, his discovery went relatively unnoticed. Yet, many similarities between the two individual's discoveries can be noted such as deficits in socialization and stereotypic movements. Perhaps the most striking similarity between Kanner and Asperger's independently discovered nearly identical disorders would be their assigned name - autism.

The term "autistic" had first been coined by a Swiss psychiatrist, Eugen Bleuler, when referencing a symptom primarily associated with schizophrenia (1913). It can be debated how both Kanner and Asperger separately encountered similar disorders and came to identify them with the same name, but more important to our discussion is the overall confusion the identical name caused for differentiation between schizophrenia and autism. To Bleuler (1913), "autistic" specified a type of thinking individuals with schizophrenia experienced, in which they perceived a distorted sense of reality, a sort of fantasy life comprised of delusions, in place of logical thinking. They withdrew from reality to the point of losing the ability to function within the everyday world and interact appropriately with those around them. Despite this symptom being only vaguely connected to the disorder of autism (e.g., the inability to relate themselves to others), confusion soon arose between the two disorders leading to the common misuse of childhood schizophrenia as a diagnosis in lieu of autism (Kanner, 1965; Rutter, 1972).

Kanner (1965) himself acknowledged that though autism shared some terminology and distant features with childhood schizophrenia, his finding was not to be confused with that of childhood schizophrenia as it was an entirely different disorder. Whereas schizophrenia can be described by a withdrawal from reality and participation in social situations, he felt children with autism were not necessarily withdrawing from participating - they had never participated in the first place.

Michael Rutter was also a supporter of the differentiation between autism and childhood schizophrenia. Rutter (1972) outlined several reasons for how the two disorders were different in addition to the evidence identified by Kanner including their course (individuals with schizophrenia experience relapse and remission whereas children with autism generally do not), the presence of delusions and hallucinations (especially 
common in those with schizophrenia, but not in autism), the presence of intellectual disability being more commonly associated with autism, and sex differences (schizophrenia is present equally in both males and females while autism is much more common in males) to name a few.

Once it had been established that autism was not just a subtype of schizophrenia, it was necessary to establish criteria to assist in accurate diagnosis of this newly identified phenomenon. Clearly, one of the first to define criteria for the disorder was Kanner. In addition to the aforementioned symptoms of impairments in socialization, communication, and preservation of sameness, Kanner also believed autistic children possessed good cognitive abilities (1943). Finally, these symptoms must be evident in the first two years of life (Kanner \& Eisenberg, 1957). Rutter (1978) later agreed with the majority of Kanner's criteria (i.e., impairment in social development, language development, and insistence on sameness), but believed the age of onset to be before 30 months of age. Additionally, Rutter believed the criteria should also take into account intellectual functioning as he found that there was often comorbidity of autism and intellectual disability - a finding that Kanner had not previously noted. Yet, these criteria were set forth by individuals and their followers rather than by a collaborative group. In order to attain accurate diagnosis across individuals, a system needed to be implemented.

The criteria for what we now know as ASDs were first officially given attention as a disorder separate from schizophrenia in the APA's Diagnostic and Statistic Manual of Mental Disorders ( $3^{\text {rd }}$ Edition; DSM-III), which was released in 1980. Here ASDs were introduced under a new term - Pervasive Developmental Disorders (PDDs). This label was used to specify the all encompassing nature of the disorder. Unlike other disorders, PDDs affected the child across multiple areas of functioning and persisted throughout life. Included in this category were Infantile Autism, Childhood Onset Pervasive Developmental Disorder, and Atypical Pervasive Developmental Disorder. To meet criteria for a diagnosis of Infantile Autism, the child had to display the following symptoms prior to 30 months of age: lack of responsiveness to others, deficits in language and communication, and bizarre responses to the environment. Additionally, they could not display delusions and 
hallucinations that are associated with schizophrenias. The remaining two disorders were designed to account for alterations from these criteria with evidence of a developmental disorder, but have been since removed.

Some modifications for ASD criteria came about in the Diagnostic and Statistic Manual of Mental Disorders ( ${ }^{\text {rd }}$ Edition - Revised; DSM-III-R) (APA, 1987). Still under the umbrella term of PDDs, Infantile Autism was changed to Autistic Disorder while Childhood Onset Pervasive Developmental Disorder and Atypical Pervasive Developmental Disorder disappeared with the addition of PDD-NOS. Autistic Disorder eliminated the age of onset criterion seen in the DSM-III by only requiring an onset in infancy or childhood. The remaining criteria were flushed out to a total of 16 within three categories - impairments in reciprocal social interaction, verbal and nonverbal communication as well as pretend play, and restricted interests and activities. Individuals had to meet a total of eight criteria with at least two in the first category and at least one in each of the second and third categories. PDD-NOS did not have set criteria, but it was stated that there should be impairment in reciprocal social interaction and verbal and nonverbal communication with the occasional presence of restricted interests and activities. Despite most revisions being considered improvements upon previous versions, the DSM-III-R was not judged as such (Tidmarsh \& Volkmar, 2003). The criteria set forth were deemed overly inclusive causing inaccurate diagnoses. Additionally, the criteria did not match those found in the International Classification of Diseases (10 $0^{\text {th }}$ Edition; ICD-10), another manual commonly used for diagnosis and classification of mental illnesses (World Health Organization [WHO], 1992).

Fortunately, the Diagnostic and Statistic Manual of Mental Disorders ( $4^{\text {th }}$ Edition; DSM-IV) incorporated advancements from the previous editions (APA, 1994). This edition retained the diagnoses of Autistic Disorder and PDD-NOS with the addition of Asperger's Disorder, Childhood Disintegrative Disorder, and Rett's Disorder. At this time, a criterion for age of onset in Autistic Disorder re-emerged and was set at 36 months for at least one of the social/communication symptoms while the items pertaining to each of the three symptom categories became more broadly defined (Richdale \& Schreck, 2008). With the exception of PDDNOS, the set of PDDs were each given detailed criteria to designate them as separate disorders (APA, 1994). PDD-NOS held its status as the all encompassing diagnosis when a PDD was evident, but a more specific PDD 
diagnosis was not warranted. The criteria set forth in the DSM-IV were found to be comparable to those set forth in the ICD-10 (WHO, 1992), an advantage for differential diagnosis world-wide. Of course, these criteria were soon revised in the current edition of the DSM, which will be thoroughly discussed in the following section.

\section{Differential Diagnosis}

It should come as no surprise that differential diagnosis among ASDs is often deemed necessary. Without its use, misdiagnosis may occur. In addition to the avoidance of misdiagnosis, there are several other benefits of differential diagnosis including targeting the causes of disorders along the spectrum, determining prognosis, and identifying the most effective treatments (Willemsen-Swinkels \& Buitelaar, 2002). Fortunately, differential diagnosis has been incorporated into the current systems of mental illness classification (APA, 2000; WHO, 1992).

The two most widely used manuals for diagnosis and classification of mental illness at this time include the APA's Diagnostic and Statistic Manual of Mental Disorders ( $4^{\text {th }}$ Edition, Text Revision; DSM-IV-TR) (2000) and the World Health Organization's International Classification of Diseases (10 ${ }^{\text {th }}$ Edition, ICD-10) (WHO, 1992). Although these two manuals do portray some differences in their classification of ASDs, it has been noted that they have progressed over time to become more similar than not (Tidmarsh \& Volkmar, 2003). This overall consensus is important for both general and differential diagnosis among clinicians and researchers so that accurate diagnoses can be made and compared world-wide to assist in future research (WillemsenSwinkels \& Buitelaar, 2002). Due to this fortunate corroboration between the two systems, this review will utilize the $D S M-I V$-TR for diagnostic and classification purposes from here on forward. Although only Autistic Disorder and PDD-NOS will be addressed herein, brief descriptions of the remaining three ASDs are also provided.

Autistic Disorder (Autism). The criteria to meet a diagnosis of autism is considered to be the most consistent with Kanner's earliest description of early infantile autism (Sevin, Knight, \& Braud, 2007). According to the DSM-IV-TR, a diagnosis of autism is warranted if an individual displays significant 
impairments in all three of the core symptom domains - social interaction, communication, and restricted and repetitive behavior, interest, or activity patterns (APA, 2000). More precisely, individuals must present with a total of at least six items with at least two deficits in social interaction (i.e., multiple nonverbal behaviors, peer relationships, spontaneous sharing of joys, accomplishments, and interests, and reciprocating socially and emotionally), one in communication (i.e., spoken language, initiating and maintaining conversations, stereotyped language, and pretend play), and one in restricted and repetitive behavior, interest, or activities (i.e., abnormal preoccupation with one or more stereotyped or restricted interests, preservation of sameness to nonfunctional routines, stereotypies, and constant fixation on parts of objects). The total number of items needed to receive a diagnosis of autism exceeding the minimum number of symptoms required within each area illustrates that these criteria are not independent from one another and also that they may not present themselves in identical patterns across individuals (Lord \& Risi, 1998). An additional prerequisite is that deficiency must be present in one of the three following areas prior to 3 years of age - social interaction, language used in social communication, or pretend play (APA, 2000). However, the diagnosis of an ASD follows a hierarchical system where specific ASD diagnoses must be ruled out before considering alternative ones (Lord \& Risi, 1998). Therefore, prior to receiving a diagnosis of autism, it must be established that the ASD does not better fit the diagnosis for Rett's Disorder or Childhood Disintegrative Disorder (APA, 2000).

Pervasive Developmental Disorder Not Otherwise Specified (PDD-NOS). Due to the hierarchical system in place, receiving a diagnosis of PDD-NOS is slightly more complex. Lying at the bottom of the hierarchy, PDD-NOS is often viewed as a catch all diagnosis and is given when the individual does not meet the criteria for any of the four more clearly defined ASDs, but still evidences impairments (APA, 2000; Lord \& Risi, 1998; Tidmarsh \& Volkmar, 2003). More specifically, an individual may receive a diagnosis of PDD-NOS following rule out of the other ASDs if they experience impairment in reciprocating socially as well as either a deficiency in a form of communication or endorsement of stereotyped behaviors (APA, 2000). This diagnosis is generally used if the individual's symptoms are subthreshold to an autism diagnosis, symptoms emerge past the autism cut-off age of 3 years, the case appears peculiar to a standard autism diagnosis, or the individual does not 
endorse the correct number of items within each of the three domains (Buitelaar, Van der Gaag, Klin, \& Volkmar, 1999). For this reason, it has been noted that PDD-NOS is more often characterized by what it is not rather than what it is; it is not autism (Matson \& Boisjoli, 2007). Indeed, the criteria for being diagnosed with PDD-NOS are not clearly outlined in the DSM-IV-TR, which makes diagnosis of PDD-NOS more ambiguous than a diagnosis of autism (APA, 2000; Buitelaar et al., 1999; Nebel-Schwalm \& Matson, 2008; Tidmarsh \& Volkmar, 2003). Despite this ambiguity, PDD-NOS has been found to occur more frequently than typical autism though it receives less attention (Chakrabarti \& Fombonne, 2005; Matson \& Boisjoli, 2007; Mayes, Volkmar, Hooks, \& Cicchetti, 1993).

Asperger's Disorder. The first description of Asperger's Disorder was by Hans Asperger in 1944, though it was not called such at the time and was commonly misinterpreted to be the same as Kanner's discovery (1991). Asperger noted several differences between the children he encountered and those in Kanner's sample. Asperger described the children he encountered as possessing social impairments, which portrayed them as odd or peculiar rather than aloof and passive. He also spoke of their characteristic manner of speaking like adults whereas Kanner mentioned severe impairments in communication above and beyond a different manner of speaking. Currently, diagnostic criteria for Asperger's Disorder require the individual to present with at least two symptoms of severe impairment in social interaction, at least one symptom of restricted repetitive and stereotyped behavior or interests, disturbances causing significant impairment in at least one critical area (e.g., social), and no evidence of language, cognitive, self-help skills, or adaptive behavior delay (APA, 2000). Furthermore, the disorder must not be better accounted for by another specific ASD or schizophrenia. Although there must be no delay in language development and abnormal speech is not common in those with Asperger's Disorder, these individuals often present with some peculiarities in terms of their communication patterns including verbosity, one-sided conversations, and poor prosody (Klin \& Volkmar, 1997).

Childhood Disintegrative Disorder (CDD). One of the least common ASDs, CDD, was first reported by Theodor Heller in 1908 (Mouridsen, 2003). Perhaps the most significant feature of CDD is the perceived 
normal development that exists for at least the first two years of life (APA, 2000). Following this normal growth period, children demonstrate a significant loss of ability in at least two of five areas prior to reaching 10 years of age - expressive or receptive language, social skills or adaptive behavior, control over bowel or bladder, play, and motor skills. They also display with abnormal functioning in at least two of the three categories an autism diagnosis merits - social interaction, communication, and restricted and repetitive behaviors and interests. Finally, the disorder must not be better accounted for by any other ASD or schizophrenia. Similar to autism, CDD is diagnosed in males more than females (Matson \& Mahan, 2009). However, the differential diagnosis of CDD from autism can be quite difficult in certain cases (Hendry, 2000). Upon examination of the DSM-IV-TR criteria for each diagnosis, it becomes evident that the disorders are nearly identical aside from the age of onset, which itself actually overlaps between diagnoses.

Rett's Disorder. An even rarer type of ASD, Rett's Disorder, was first described by Andreas Rett in 1966 when he encountered 22 females who repetitively engaged in hand-wringing behavior (Chahrour \& Zoghbi, 2007). Unfortunately, this discovery went relatively unnoticed in English-speaking countries for many years. To date, Rett's Disorder remains one of the least studied ASDs (Matson, Fodstad, \& Boisjoli, 2008). Despite this, research has uncovered that mutations in the X-linked gene, MECP2, encoding the methyl-CpGbinding protein 2, MeCP2, are what cause this debilitating disorder (Amir et al., 1999). It was originally thought that Rett's Disorder could only occur in females as the mutation was suspected to be lethal in males in the embryonic stage. However, more recent research has demonstrated that it is possible for males to be born with this mutation although it remains extremely rare and may often go undetected or misdiagnosed (Sharma, 2009).

In order to meet criteria for a diagnosis of Rett's Disorder, individuals must appear to develop normally in the prenatal and perinatal periods, demonstrate normal psychomotor development for at least the first 5 months of life, and be born with a normal head circumference (APA, 2000). Succeeding this apparently normal growth period, children must experience each of the following symptoms within the designated time frame, if applicable: decelerated head growth between 5 and 48 months of age, loss of previously acquired purposeful hand skills between 5 and 30 months of age followed by emergence of stereotyped hand movements (e.g., hand- 
wringing), early loss of social engagement, poor coordination of gait or trunk movements, and severe impairment in both expressive and receptive language as well as psychomotor retardation.

\section{Prevalence}

In recent years, there has been great concern and debate over whether or not the prevalence of ASDs is rising (Chakrabarti \& Fombonne, 2001, 2005; Herbert, Sharp, \& Gaudiano, 2002; Nicholas et al., 2008;

Tidmarsh \& Volkmar, 2003; Willemsen-Swinkels \& Buitelaar, 2002; Williams, Mellis, \& Peat, 2005; Wing \& Potter, 2002). When ASDs were first discovered, the disorder was considered to be extremely rare. Early estimates of the prevalence of ASDs varied only slightly with averages said to be between 2 and 6 in 10,000 (Chakrabarti \& Fombonne, 2001; Sevin et al., 2007; Willemsen-Swinkels \& Buitelaar, 2002; Wing \& Potter, 2002). Unfortunately, current research suggests a relative increase in the prevalence of ASDs with the most widely accepted average being approximately 60 in 10,000 (Nicholas et al., 2008; Sevin et al., 2007; Tidmarsh \& Volkmar, 2003; Willemsen-Swinkels \& Buitelaar, 2002). This average is occasionally debated with reviews of more recent studies (i.e., those from the 1990s and later) having found prevalence rates ranging from 3.8 to 72.6 per 10,000 (Fombonne, 2005; Williams et al., 2005). The majority of these prevalence studies focus on the collection of ASDs as a whole rather than on each of the five spectrum disorders separately; however, recent studies have begun to tease apart the prevalence of each of the ASDs.

Presently, PDD-NOS is considered to be the most prevalent ASD with research suggesting rates of 21 to 36.1 per 10,000 individuals (Chakrabarti \& Fombonne, 2001, 2005; Fombonne, 2005; Howlin, 2006). This status appears appropriate since, as was aforementioned, PDD-NOS is often considered the catch all diagnosis when clinicians believe an ASD diagnosis is relevant, but all specific criteria for one of the other four ASDs has not been met (APA, 2000; Lord \& Risi, 1998; Tidmarsh \& Volkmar, 2003). Following PDD-NOS in order of most prevalent is autism with rates of 13 to 22 per 10,000 (Chakrabarti \& Fombonne, 2001, 2005; Fombonne, 2005; Howlin, 2006). Asperger's Disorder, the next most diagnosed ASD, occurs at a rate of 8.4 to 11 per 10,000 with the most conservative rate being 2.6 per 10,000 individuals. The final two ASDs are found at significantly lower rates. CDD occurs at rates ranging from .6 to 2 per 10,000 while Rett's Disorder, the least 
common of the ASDs, is only found in 1 per 20,000 individuals (Chakrabarti \& Fombonne, 2005; Fombonne, 2005; Tidmarsh \& Volkmar, 2003). In addition to these specific prevalence rates, it should also be noted that ASDs are much more common in boys than girls with a ratio average of 4.3:1 (Fombonne, 2005).

Despite this data, it remains controversial whether or not this apparent increase in the overall prevalence of ASDs is actually occurring or if it might be due to other factors (Tidmarsh \& Volkmar, 2003; Williams et al., 2005; Wing \& Potter, 2002). One of the more significant proponents in favor of other factors is the ever changing criteria for ASDs. As was aforementioned, ASDs were not included in the APA's DSM until 1980 leaving specific diagnostic criteria, more or less, in the hands of clinicians and researchers prior to this time. Subsequently, the diagnostic criteria continued to change with each new release of the manual (APA, 1980, 1987, 1994, 2000). These continual revisions resulted in studies utilizing different criteria when assessing the prevalence of ASDs, thus increasing the possibility for a misinterpreted increase (Williams et al., 2005; Wing \& Potter, 2002). Additionally, comparing different studies often produces confounds such as differences in the size of the target population and the methods of participant recruitment, among others.

Another noteworthy factor to consider when reviewing research demonstrating increases in the rates of ASDs is the substantial increase in autism awareness and service provision in recent years. As ASDs are frequently discussed in the media, especially with the concern over vaccinations being the cause or trigger of such disorders, parents are becoming more aware of ASDs (Wing \& Potter, 2002). This increased awareness may lead parents to have their children assessed when they may have not previously done so. Additionally, since services have simultaneously increased and improved with this awareness, an ASD diagnosis may now also be more accepted by both parents and clinicians. 


\section{Challenging Behaviors and Autism Spectrum Disorders}

\section{Background}

Challenging behaviors, also commonly referred to as maladaptive behaviors, aberrant behaviors, problem behaviors, and atypical behaviors, among an assortment of other terms, are deemed quite common within ASD cases. In fact, it has been established that the majority of individuals carrying a diagnosis of an ASD evince at least one challenging behavior (Matson \& Nebel-Schwalm, 2007; Mudford et al., 2008). Although no formally agreed upon operational definition of challenging behavior currently exists due to its absence in the DSM-IV-TR, with the exception of stereotypies, its general defining characteristics include the behavior being exhibited frequently or intensely and posing hardship to the individual's caregivers or support network while interfering with the individual's learning (Emerson et al., 2000; Mudford et al., 2008).

Challenging behaviors may also threaten the physical safety of the individual and those around him, thus limiting participation in community activities, which as a result may hinder learning (Emerson, 2005).

Challenging behaviors are evinced by various individuals in the general population including those with diagnoses of an ASD, intellectual disability (ID), psychiatric disorder, language or communication disorder, and even those without a diagnosis (Dominick, Ornstein Davis, Lainhart, Tager-Flusberg, \& Folstein, 2007; Emerson et al., 2001; Kravitz \& Boehm, 1971; McClintock, Hall, \& Oliver, 2003). The prevalence of these behaviors within the ASD population is considerable. Recent prevalence estimates range from 35.8\% to $94.3 \%$, with the majority of studies identifying at least half of individuals with ASD engaging in challenging behaviors (Baghdadli, Pascal, Grisi, \& Aussilloux, 2003; Bodfish, Symons, Parker, \& Lewis, 2000; Holden \& Gitlesen, 2006; Matson, Wilkins, \& Macken, 2009; Murphy, Healy, \& Leader, 2009). Furthermore, a study looking at learning disabled individuals who evinced challenging behaviors found that $19 \%$ of the adults and children also carried ASD diagnoses (Lowe et al., 2007). Overall, these rates are substantially higher than individuals solely carrying an ID diagnosis who demonstrate prevalence rates ranging from 10\% to 20\% (Emerson et al., 2001; Holden \& Gitlesen, 2006; Lowe et al., 2007). Additionally, as should be expected, individuals diagnosed with both ASD and ID exhibit more challenging behaviors than those with ID alone (Matson, Fodstad, \& Rivet, 
2009). Even more interesting research is beginning to emerge looking at relationships between the severity of ASD and the presence of challenging behaviors with preliminary results suggesting a higher prevalence rate among those with more severe cases of ASD (Matson, Wilkins, \& Macken, 2009; Rojahn et al., 2009). However, these studies did not investigate significant differences, leaving the question still unanswered. Despite the absence of challenging behaviors being listed as a criterion for a diagnosis of an ASD, given its high prevalence within the population, most referrals for treatment are initially made based on these issues (Mudford et al., 2008). This appears warranted due to the abundance of negative effects challenging behaviors can have not only on the individual, but on their family, staff, and community. Clearly, challenging behaviors such as self-injury, pica, and physical aggression can pose serious threats to the physical safety of the individual and others. Taking into account extreme cases, these actions may even result in death (Mukaddes \& Topcu, 2006). Destructive behaviors that lead to property damage have monetary repercussions that may create financial hardship for the family and community. In addition, there are many other consequences to challenging behavior that may receive less attention by everyday observers. Even stereotypy, an apparently harmless challenging behavior, can result in severe consequences for the individual. In addition to other challenging behaviors, stereotypy consumes a great degree of the individual's attention, which can cause interruptions in the learning process (MacDonald et al., 2007; Matson \& Nebel-Schwalm, 2007; Mudford et al., 2008). Therefore, such seemingly harmless challenging behaviors such as stereotypy can severely impair an individual's intellectual and functional abilities by not providing them with opportunities typical peers generally have. Furthermore, various challenging behaviors result in stigmatization and fear by others, which can cause for a decrease in socialization opportunities and community involvement thereby inhibiting advancement in these skill areas (Luiselli \& Slocumb, 1983). Unfortunately, abuse and neglect by others are also consequences of challenging behaviors (Mudford et al., 2008). Although this is not an exhaustive list of all possible consequences of challenging behaviors, it illustrates many reasons for concern.

With so many possible consequences resulting from challenging behaviors, the causes of such behavior need to be addressed. According to Scarborough and Poon (2004), the behavior of children with developmental 
disabilities can be inherent, learned, or an interaction of inherent and learned behavior. Frequently referred to as the function, environmental variable, or maintaining variable/contingency of a behavior, the causes of challenging behaviors are often taken into consideration when providing treatment (Matson \& Minshawi, 2007; Mudford et al., 2008). An assortment of variables can be ascribed as the maintaining function of challenging behaviors including attention, escape, non-social reinforcement, tangible reinforcement, and physical discomfort. The function of a behavior is derived through a functional assessment, which can be accomplished using three separate methods - experimental manipulation of antecedents and consequences in a structured environment, direct observation of antecedents and consequences in the natural environment, and indirect/informant assessment (Martin, Gaffan, \& Williams, 1999). Although naturalistic observations (i.e., antecedent, behavior, consequence $[\mathrm{ABC}]$ checklists) are occasionally used, experimental functional analysis and checklists for functional assessment appear to be the most popular methods at deriving the function of challenging behaviors.

Experimental functional analysis (EFA) is often considered the standard method of assessment for the function of a behavior and is also the most studied. EFA involves experimental manipulation of antecedents and/or consequences that are potentially maintaining the challenging behavior (Martin et al., 1999; Matson \& Minshawi, 2007; Sturmey, Seiverling, \& Ward-Horner, 2008). This can also be referred to as an analog assessment and typically involves randomization of conditions. Iwata, Dorsey, Slifer, Bauman, and Richman (1982) brought EFA to the forefront with their eminent publication assessing the function of self-injurious behaviors in developmentally disabled individuals. Many more studies followed this publication with modifications to the technique including sample size, number and type of conditions, time of each condition, number of replications, and order of conditions (Martin et al., 1999). Despite the popularity of EFA, psychometric data are not readily available and those which are available are variable with some authors indicating good to excellent validity and reliability while others do not (Calloway \& Simpson, 1998; Martin et al., 1999; Toogood \& Timlin, 1996). Unfortunately, some critiques of the utility of EFA extend past psychometrics. The procedure itself is very labor-intensive as it can often become a lengthy assessment with 
some estimates reaching several hours (Matson \& Minshawi, 2007). The required level of training and number of materials needed for the assessment may also be unavailable. Another pertinent problem is that repeated exposure may lead to new learning during the assessment (Martin et al., 1999). This can confound the results, require even more lengthy assessments, and introduce challenging behaviors in situations which they would otherwise not have been seen.

To counter some of the difficulties seen with EFA, an area of research has evolved contributing to the development of checklist scales to be used in lieu or conjunction with EFA. The Motivation Assessment Scale $(M A S)$ was the first attempt at this feat with self-injurious behavior being assessed (Durand \& Crimmins, 1988). The MAS is a questionnaire consisting of 16 questions to determine if the challenging behavior is being maintained by attention, escape, tangible, or sensory consequences. Each item is rated on a scale from 0 (never) to 6 (always). The authors report good inter-rater and test-retest reliability; however, attempts to replicate have failed and additional research to counter these failures is lacking (Sigafoos, Kerr, \& Roberts, 1994; Zarcone, Rodgers, Iwata, Rourke, \& Dorsey, 1991). Therefore, the use of the MAS is discouraged at this time unless done so in conjunction with alternative forms of functional assessment.

Following the development of the MAS, the Questions About Behavioral Function (QABF) emerged (Paclawskyj, Matson, Rush, Smalls, \& Vollmer, 2000). Similar to the $M A S$, the $Q A B F$ is a questionnaire consisting of 25 statements for which ratings of 0 (not at all) to 3 (often) can be assigned for statements pertaining to functions of attention, escape, non-social contingencies, physical discomfort, and tangible reinforcement. Psychometric data, including inter-rater reliability, test-retest reliability, internal consistency, and construct validity, is promising (Matson, Bamburg, Cherry, \& Paclawskyj, 1999; Nicholson, Konstantinidi, \& Furniss, 2006; Paclawskyj et al., 2000). As with many functional assessments, all functions are not addressed with this questionnaire and it may be beneficial to use it in conjunction with an alternative method, such as an EFA. However, Matson et al. (2003) have more recently developed a scale known as the Functional Assessment for multiple CausaliTy (FACT) to aid the $Q A B F$ if a distinct function cannot be identified (e.g., there are multiple functions). This scale assesses for the same functions as the $Q A B F$ (i.e., attention, escape, non-social 
contingencies, physical discomfort, and tangible reinforcement), but does so by requiring a forced-choice between functions. The authors report good internal consistency in the original paper; however, follow-up studies have not yet been conducted. Therefore, this assessment should be used with caution and in conjunction with other methods.

\section{Topography}

Aggressive Behaviors. The definition of aggressive behaviors is quite variable given the possible inclusion and exclusion of different topographies, leaving its operational definition inconclusive (Crocker et al., 2006). Aggressive behavior is commonly viewed as solely physical aggression by which an individual physically attempts to or successfully harms another. Examples of some common topographies of physical aggression include hitting with an open or closed hand, scratching, pinching, kicking, biting, pushing, and pulling hair (Alink et al., 2006; Crocker et al., 2006; Singh et al., 2006). However, several other topographies can be included in the category of aggressive behavior such as verbal aggression (e.g., threatening to harm others, bullying, cursing at others, and screaming or yelling at others), sexual aggression (e.g., masturbating in public, fondling others, and exposing oneself in public), property aggression (e.g., throwing objects, kicking objects, and urinating/defecating on the floor or on objects), and self-directed aggression (e.g., hitting self and banging head on objects) (Crocker et al., 2006; Montes \& Halterman, 2007). Although self-directed aggression can be considered an aggressive behavior, these specific topographies will be discussed as self-injurious behaviors in a later section.

Typically developing children begin engaging in aggressive behavior when they are as young as 1-yearold with prevalence estimates of approximately 50\% (Alink et al., 2006). These aggressive behaviors continue to increase in children ages 2 and 3 years with prevalence estimates ranging from $68 \%$ to $80 \%$, with rates beginning to decline following 3 years of age. Though boys are known to engage in aggressive behaviors at higher rates than girls, both genders follow this same developmental trend during infancy and toddlerhood. However, while boys ages 5 to 11 years demonstrate an average of $3.7 \%$ prevalence rate of aggressive behavior following toddlerhood, girls ages 5 and 11 years continue to follow a downward trend with $2.3 \%$ and $.5 \%$ 
prevalence rates, respectively (Lee, Baillargeon, Vermunt, Wu, \& Tremblay, 2007). Moreover, data collected across countries found that the prevalence of general aggression in children and young adults ages 3 to 20 ranges from $0 \%$ to $24.5 \%$ with variations seen across gender. In terms of another form of aggressive behavior, $18.8 \%$ of children in the $6^{\text {th }}$ through $12^{\text {th }}$ grades admit to having engaged in bullying behavior during the course of a year (Carlyle \& Steinman, 2007). Therefore, it appears aggressive behavior presents itself relatively commonly within the typically developing population in multiple forms.

Although aggressive behavior is relatively common within the typically developing population, individuals possessing a diagnosis of an ID or ASD present with even higher rates. Overall, it has been found that $17.6 \%$ to $60 \%$ of individuals with ID evince aggressive behavior, with most rates falling in the $20 \%$ to $40 \%$ range (Crocker et al., 2006; Lindsay et al., 2004; Tenneij \& Koot, 2008). More specifically, physically aggressive behavior has been found to occur in $12.6 \%$ to $35.67 \%$ of adults with ID (Crocker et al., 2006; Hemmings, Gravestock, Pickard, \& Bouras, 2006; Tenneij \& Koot, 2008; Tyrer et al., 2006). Verbal aggression has also been found to occur at high rates by those with ID with research demonstrating prevalence rates of $16.4 \%$ to $44.33 \%$ among adults (Crocker et al., 2006; Hemmings et al., 2006; Tenneij \& Koot, 2008). Although other forms of aggression are less studied within the ID population, researchers have found that $15 \%$ of adults with ID evince destructive behaviors (Hemmings et al., 2006), and that $24 \%$ of adults with ID engage in property destruction and $9.8 \%$ in sexual aggression (Crocker et al., 2006).

However, it is not only the difference in rates that stands out between typically developing individuals and those with ID. Even though aggressive behavior is frequently found to be higher among males than females in the typically developing population, studies of aggressive behavior in the ID population vary between males exhibiting higher rates and there being no significant differences (Crocker et al., 2006; Hemmings et al., 2006; Tenneij \& Koot, 2008; Tyrer et al., 2006). Furthermore, it has frequently been established that aggressive behavior increases with the severity of ID (Allen, 2000; Tyrer et al., 2006). Overall, it is clear that these rates are substantially higher than those presented by typically developing individuals; however, the factor of autism 
comorbidity may not always be accounted for in these studies (Hemmings et al., 2006). Fortunately, some studies exist focusing solely on those with ASDs.

Research demonstrating prevalence rates of aggressive behavior in those with ASDs focuses predominantly on children, which is more than likely due to the general focus on children with ASDs as opposed to adults in the literature. One such study found that $50 \%$ of children ages 2 through 17 evince aggressive behavior toward others (Matson, Wilkins, \& Macken, 2009). Additionally, another study judging clinical significance of behaviors stated that $22.5 \%$ of children ages 1.5 to 5.8 years with an ASD engage in aggressive behavior (Hartley, Sikora, \& McCoy, 2008). However, since the presence of aggressive behavior was only reported if it was deemed clinically significant, it can be assumed that a higher percentage of children in the study evinced aggressive behavior in general that was not judged as significant. The $22.5 \%$ of the sample the study referenced most likely demonstrated more severe rates and intensities of aggression than typically developing controls. Finally, bullying has been demonstrated by $44 \%$ of children with an ASD ages 4 through 17 (Montes \& Halterman, 2007).

Once again, gender differences have briefly been addressed in the ASD literature in regards to aggressive behavior. Some have found that there are no significant differences between genders (Murphy et al., 2009); while others claim males exhibit greater aggression than females (McClintock et al., 2003). Therefore, as was seen within the ID population, significant gender differences are controversial and need to be investigated further. This question is even more intriguing when taking into consideration the greater chance of typically developing males evincing aggression combined with the greater chance of males carrying an ASD diagnosis.

Overall, it is clear that a significantly greater percentage of those with ASDs engage in aggressive behavior compared to typically developing individuals, and that those with ID also appear to demonstrate relatively lower prevalence rates overall when compared to those with ASDs. The close rates between those with ASD and ID can be explained by the factor of autism comorbidity not always being separated within ID studies, as well as the general presence of comorbidity within these populations (Matson \& Shoemaker, 2009). 
Stereotypies and Repetitive Behaviors. Despite being the only challenging behaviors evinced by those with ASDs that are incorporated into the diagnostic criteria, stereotypies and repetitive behaviors are often not taken into account when discussing challenging behaviors. However, these behaviors do meet the operational definition of a challenging behavior and often require treatment (Loftin, Odom, \& Lantz, 2008; Rapp \& Vollmer, 2005). Additionally, parent ratings of stress level have been found to be highly correlated with the presence of repetitive behaviors in their children carrying ASD diagnoses, further supporting the need for attention (Gabriels, Cuccaro, Hill, Ivers, \& Goldson, 2005). The definition of stereotypy is often debated regarding its details, but overall stereotypy is defined as repetitive motor and/or vocal behavior that does not appear to serve an adaptive function (MacDonald et al., 2007). Examples of motor stereotypy include handflapping, body rocking, staring at objects, spinning objects, abnormal positioning of body parts, and restricted play/leisure behavior (MacDonald et al., 2007; Singer, 2009). Vocal stereotypy generally consists of non-functional sounds, repetition of words or phrases, unprovoked laughing or giggling, and echolalia (MacDonald et al., 2007). Research is beginning to emerge using animal models and brain imaging techniques to identify brain mechanisms playing a role in stereotypy and repetitive behaviors. The basal ganglia, and more specifically the caudate nucleus, has revealed abnormalities within those engaging in stereotypy and restricted, repetitive behaviors (Lewis \& Bodfish, 1998; Lewis, Yanimura, Lee, \& Bodfish, 2007; Sears et al., 1999). However, the exact link between these abnormalities and those with autism is still inconclusive.

Although stereotypy is most often attributed to individuals with ASDs, it is relatively common for individuals with ID and also typically developing individuals, especially infants and toddlers, to exhibit stereotypy (Carcani-Rathwell, Rabe-Hasketh, \& Santosh, 2006; MacDonald et al., 2007; Matson \& Dempsey, 2008). However, differences in frequency have often been noted. Children with ASDs tend to exhibit stereotypy at a slightly higher frequency at the age of 2 years when compared to their typically developing peers (MacDonald et al., 2007). This gap increases considerably at ages 3 and 4 years so that children with ASDs begin to exhibit stereotypy at significantly higher rates than their same-aged typically developing peers. Overall, 
it appears that children with ASDs increase their rates of stereotypy over time while typically developing individuals decrease their rates.

It has also been repeatedly found that children carrying a diagnosis of an ASD, either with or without a comorbid ID, display a higher frequency of stereotypy than those individuals carrying only a diagnosis of ID (Carcani-Rathwell et al., 2006; Matson \& Dempsey, 2008). Similarly, children with an ASD exhibit more motor stereotypy than atypically developing children without an ASD diagnosis (Goldman et al., 2009). In conjunction with these findings, two sets of stereotypies have been identified that appear to differentiate ASD from nonASD individuals - hand/finger stereotypies (e.g., tapping, opening-closing, clapping, waving) and stereotypical gait patterns (e.g., skipping, spinning, jumping). Furthermore, preliminary research differentiating between the stereotypies displayed by those with autism and PDD-NOS indicates that children with autism engage in stereotypies at a higher frequency than those with PDD-NOS (Matson \& Dempsey, 2008).

Unfortunately, there is a paucity of research examining gender differences in relation to stereotypies, both within the ASD population and among other individuals. Within the typically developing child population, no significant gender differences have been found (Harris, Mahone, \& Singer, 2008). However, research examining gender differences within the ASD population has found that there is a tendency for males to engage in more stereotypic behaviors than females, although these differences may not be significant (Nicholas et al., 2008). Therefore, it is currently inconclusive whether or not there are differences in endorsement rates of stereotypies between genders.

Self-Injurious Behaviors (SIB). The definition of SIB, perhaps one of the most troubling and dangerous challenging behaviors exhibited by those with ASDs, is somewhat debatable. The most widely accepted definition of SIB states that the individual's behavior results in physical injury, evident by the presence or likelihood of tissue damage if not stopped, to one's own body (Rojahn, Schroeder, \& Hoch, 2008; Schroeder, Mulick, \& Rojahn, 1980; Tate \& Baroff, 1966). The presentation of SIB varies greatly across individuals with the three most common forms being hitting oneself, banging one's head/face, and biting oneself (Iwata et al., 1994). Additional forms of SIB include self-pinching, self-scratching, self-choking, hand 
mouthing, pica, self-poking, hair pulling, self-kicking, self-restraint, banging one's body, rumination, eye gouging, and stuffing one's orifices, among others (Iwata et al., 1994; Schroeder et al., 1980).

As is true of many challenging behaviors, SIB is not only exhibited by those with ASDs. Typically developing infants are also reported to engage in SIB during their first year of life with $7 \%$ engaging in head banging behavior (Kravitz \& Boehm, 1971). Most incidents of head banging reported in this sample were also noted to co-occur with teething episodes, suggesting a relationship to physical discomfort or pain. Possibly due to the infrequent occurrence of SIB in typically developing individuals and the difficulty with acquiring estimates (e.g., due to self-mutilation in secrecy), very little research continues to focus on the prevalence of SIB in this population (Rojahn et al., 2008). These behaviors also exist in the ID population with prevalence estimates of $3 \%$ to $25 \%$ across different residential settings, age groups, and levels of intellectual functioning (Murphy, Hall, Oliver, \& Kissi-Debra, 1999; Oliver, Murphy, \& Corbett, 1987; Rojahn et al., 2008). Within the ID population, it appears that higher prevalence rates are associated with a decrease in intellectual functioning as one study found that of ID individuals engaging in SIB, $40 \%$ were profound, $49 \%$ were severe, and $12 \%$ were mild in intellectual functioning based on approximations (Oliver et al., 1987). Rojahn et al. (2008) found a similar trend with prevalence estimates of $25 \%$ for profound ID, $15.5 \%$ for severe ID, $7 \%$ for moderate ID, and 4\% for mild ID. Additionally, a meta-analysis conducted by McClintock et al. (2003) found similar results stating that SIB is more common among those with a severe or profound ID as compared to a mild or moderate ID.

Individuals with ASDs appear to evince higher rates of SIB than both typically developing and intellectually disabled individuals. When matched on age, gender, and IQ, approximately 50\% of adults with ASDs were found to engage in SIB compared to only approximately $25 \%$ of adults with ID alone (Bodfish et al., 2000). However, the number of topographies evinced by these individuals was not found to be significantly different across group. Within the ASD child population, 53\% of individuals 2 to 7 years of age have been found to evince SIB (Baghdadli et al., 2003). Therefore, it appears that prevalence rates are relatively consistent 
across age groups, and that these rates are considerably higher than individuals not carrying an ASD diagnosis, including those with ID alone.

As was the case with stereotypic and repetitive behaviors, differences in endorsement rates of SIB between genders have rarely been examined. Gender difference research is even sparser when considering only those with ASDs. However, there has been a minimal amount of research within the ID population. These researchers have found that there are no gender effects in relation to the presence of SIB (Holden \& Gitlesen, 2006; Lowe et al., 2007; McClintock et al., 2003).

\section{Assessment}

Given the high frequency of challenging behaviors within the ASD population, and the extensive list of consequences that can arise due to these behaviors, assessment of challenging behaviors is imperative. Several instruments currently exist to assess for challenging behaviors in the general population and those with ID and other developmental disabilities. These scales are administered to the parent or caregiver of the individual to be assessed. Examples of such assessments include the Aberrant Behavior Checklist (Aman, Singh, Stewart, \& Field, 1985a), Behavior Problems Inventory (Rojahn, Matson, Lott, Esbensen, \& Smalls, 2001), and Nisonger Child Behavior Rating Form (Aman, Tassé, Rojahn, \& Hammer, 1996). These scales are frequently utilized in the assessment of those with ASD; however, challenging behavior assessment measures designed specifically for those carrying diagnoses of ASDs are lacking. Fortunately, recent assessments developed specifically for those with ASDs have emerged and include the PDD Behavior Inventory (Cohen, Schmidt-Lackner, Romanczyk, \& Sudhalter, 2003), Autism Spectrum Disorder-Behavior Problems for Adults (Matson \& Rivet, 2007, 2008), Autism Spectrum Disorders-Behavior Problems for Children (Matson, Gonzalez, \& Rivet, 2008), Children's Scale of Hostility and Aggression: Reactive/Proactive (Farmer \& Aman, 2009), and the Baby and Infant Screen for Children with aUtIsm Traits-Part 3 (Matson, Wilkins, Sevin et al., 2009). However, many of these scales are still in their infancy, thus requiring the use of the previously mentioned assessment measures not specifically designed for those with ASD. 
Aberrant Behavior Checklist (ABC). The $A B C$ is a 58 item instrument that was originally designed to assess treatment effects, especially psychotropic drug effects, in those functioning within the severe or profound range of intellectual disability by measuring aberrant behaviors (Aman et al., 1985a). This scale was later revised to remove phrases that alluded to institutional settings so the instrument would be acceptable to use in other populations; it was re-named the Aberrant Behavior Checklist-Community (Aman \& Singh, 1994, as cited in Brown, Aman, \& Havercamp, 2002). Each item is rated on a 4-point scale from 0 (not at all a problem) to 3 (the problem is severe) considering the individual's behavior during the past month. Five subscales have been derived from this measure following a factor analysis and include Irritability, Agitation, Crying; Lethargy, Social Withdrawal; Stereotypic Behavior; Hyperactivity, Noncompliance; and Inappropriate Speech (Aman et al., 1985a). This factor structure has been validated across cultures as the same factor structure was produced when the measure was utilized in American facilities as compared to the scale's origin country, New Zealand (Aman, Richmond, Stewart, Bell, \& Kissel, 1987). Examples of items along these five subscales include cries and screams inappropriately, resists any form of physical contact, rocks body back and forth, disturbs others, and repetitive speech, respectively (Aman et al., 1985a). Psychometric properties suggest this scale is an appropriate instrument for use with the intellectually disabled with internal consistency and test-retest reliability being very good, inter-rater reliability being moderate, and convergent and divergent validity having been established (Aman, Singh, Stewart, \& Field, 1985b).

However, although this measure is validated for use with the intellectually disabled, validation of the measure for those with ASD was not possible during its construction since no comparable measure for the ASD population existed at that time. Yet, the $A B C$ has frequently been utilized in the ASD population to compare aberrant behaviors between individuals, measure aberrant behaviors over time, and also to assess psychotropic drug effects (Carey et al., 2002; Cuccaro et al., 2007; Fatemi, Realmuto, Khan, \& Thuras, 1998; Green, O'Reilly, Itchon, \& Sigafoos, 2005; Mount, Hastings, Reilly, Cass, \& Charman, 2002; Willemsen-Swinkels, Buitelaar, van Berckelaer-Onnes, \& van Engeland, 1999). In light of this, the $A B C$ has recently undergone confirmatory factor analysis to identify if its current five factor model is a good fit for use with those carrying 
ASD diagnoses (Brinkley et al., 2007). Results indicate that the current factor structure is robust within the ASD population; however, preliminary research shows that a four factor model may be more efficient for use in the ASD population. This four factor structure consists of Lethargy, Stereotypy, Disruptive Behavior, and SelfInjury. Many items from the Irritability subscale combined with those along the Hyperactivity subscale to produce the Disruptive Behavior subscale, while the remaining Irritability items became a Self-Injury subscale. These findings are interesting, but should be explored further with other research also focusing on generating psychometric properties for the $A B C$ in the ASD population. All in all, the $A B C$ is a convenient measure for use in the ASD population to assess challenging behaviors at this time in spite of these drawbacks. However, not all of the items along this measure refer to challenging behaviors as they have been defined above, leaving room for refinement in order to establish an instrument designed to assess challenging behaviors typically seen within the ASD population.

Behavior Problems Inventory (BPI-01). Although the BPI-O1 is not solely designed to assess for challenging behaviors in those with ASD specifically, the instrument measures self-injury, aggression/destruction, and stereotypy in those with intellectual disability and other developmental disabilities in general (Rojahn et al., 2001). The BPI-01 contains 52 items with 14 items pertaining to SIB, 11 to aggressive/destructive behavior, and 24 to stereotypy, as well as 1 additional item along each of the 3 subscales to accommodate for general displays of each problem behavior that do not meet the specific criteria per any particular item. This three factor model has been validated through replication (Sturmey, Sevin, \& Williams, 1995). Each item on the scale is rated along a frequency scale with a score of 0 (never), 1 (monthly), 2 (weekly), 3 (daily), or 4 (hourly), and along a severity scale with a score of 0 (no problem), 1 (slight problem), 2 (moderate problem), or 3 (severe problem) (Rojahn et al., 2001). In terms of its psychometric properties, the BPI-01 has excellent between-interviewer agreement, good test-retest reliability, and has been found to be a valid measure for assessing challenging behaviors in those with intellectual disability and other developmental disabilities, including ASDs. Additionally, the measure has been cross-validated with the previously mentioned $A B C$, which found that high scores on one measure coincided with high scores on the other (Rojahn, Aman, 
Matson, \& Mayville, 2003). A replication and extension of the BPI-01's psychometric properties was also completed and resulted in further accounts of good reliability as well as good to modest validity between the BPI-01 and ABC (Sturmey, Fink, \& Sevin, 1993). Overall, the BPI-01 appears to be a reliable and valid measure for assessing one of the populations of its intent - those with developmental disabilities. However, the measure lacks specificity on the ASD population as it focuses on intellectual and developmental disabilities as whole, which can be seen as a drawback for its use with the ASD population.

Nisonger Child Behavior Rating Form (Nisonger CBRF). The Nisonger CBRF is an adapted version of the original Child Behavior Rating Form and is used to identify challenging behaviors as well as adaptive behaviors in intellectually disabled children ages 3 to 16 (Aman et al., 1996). There are two versions of this measure - the parent and teacher versions. Both versions contain Social Competence and Problem Behaviors sections (Tassé, Aman, Hammer, \& Rojahn, 1996). The Social Competence section contains 10 adaptive behavior items along 2 subscales, which are rated on a 4-point Likert scale from 0 (not true) to 3 (completely or always true). The Problem Behaviors section varies on each version, but consists of 6 subscales each with items pertaining to challenging behaviors which are also rated on a 4-point Likert scale from 0 (did not occur or was not a problem) to 3 (occurred a lot or was a severe problem), but on 2 domains - rate of occurrence and severity. On the parent version, the six subscales are Conduct Problem, Insecure/Anxious, Hyperactive, SelfInjury/Stereotypic, Self-Isolated/Ritualistic, and Overly Sensitive. The teacher version differs in that the final scale, Overly Sensitive, is eliminated with the replacement of Irritable. In reference to the Problem Behaviors section, the part most relevant to this study, inter-rater reliability has been judged as adequate while convergent validity was established between the Nisonger $C B R F$ and the previously reviewed $A B C$ (Aman et al., 1996). Additionally, the factor structure has been found to be acceptable within the ASD population; however, it appears that a five factor model for each version is a better fit by eliminating the Overly Sensitive and Irritable scales from the parent and teacher versions, respectively (Lecavalier, Aman, Hammer, Stoica, \& Mathews, 2004). In each of these cases, the majority of the items on these original subscales load onto the Conduct 
Problem subscale. However, further research needs to be conducted in order to verify that this measure is truly acceptable to use with the ASD population.

PDD Behavior Inventory (PDDBI). The PDDBI is a measure designed specifically for use in the ASD population to assess adaptive and maladaptive behaviors (Cohen et al., 2003). As with the Nisonger CBRF, there is also a parent and teacher version of this instrument. The parent version contains ten a priori defined subscales with a total of 176 items while the teacher version is composed of eight a priori defined subscales with 144 items. The maladaptive behavior subscales on the parent version include Sensory/Perceptual Approach Behaviors, Specific Fears, Arousal Problems, Aggressiveness, Social Pragmatic Problems, and Semantic/Pragmatic Problems. The teacher version eliminates the Specific Fears and Arousal Problems subscales due to a lack of knowledge in these areas while replacing Aggressiveness with Behavior Problems. Additionally, both versions contain adaptive behavior subscales consisting of Social Approach Behaviors; Learning, Memory, and Receptive Language; Phonological Skills; and Semantic/Pragmatic Ability. A factor analysis later conducted on these a priori subscales indicate this model may not be the best fit, but further research is yet to be conducted in order to establish revised subscales. Currently, each item is rated on a 4-point Likert scale as 0 (never), 1 (rarely), 2 (sometimes/partially), or 3 (often/typically). However, the authors also include a rating of "U" for behaviors the individual used to but no longer does as well as a rating of "?" for unknown answers. Both of these ratings are counted as 0 (never) in the ratings, but may be useful for clinical purposes. Tests of psychometric properties indicate that internal consistency for all subscales is good; however, inter-rater reliability is higher between teachers than between parents and teachers. Additionally, inter-rater reliability is higher on the adaptive behavior scales when compared to the maladaptive behavior scales. Finally, the $P D D B I$ has been validated against the Nisonger $C B R F$ for similar maladaptive behavior items (Cohen, 2003). Unfortunately for the purposes of this study, the PDDBI's maladaptive behavior items are not focused on challenging behaviors as they have been defined above. 
Autism Spectrum Disorders-Behavior Problems for Adults (ASD-BPA). The ASD-BPA is the first, and currently only, challenging behavior assessment instrument to be developed specifically for adults with ASDs, and also for those with comorbid ID (Matson \& Rivet, 2007, 2008). This measure is part of a larger, comprehensive assessment battery designated for adults with ASD that includes the Autism Spectrum Disorders-Diagnosis for Adults and Autism Spectrum Disorders-Comorbidity for Adults. The scale consists of three subscales - Aggressive/Destruction, Disruptive Behavior, and Self-Injurious Behavior - totaling 19 items, which can be rated 0 (not a problem, no impairment) or 1 (problem, impairment). Examples of items on each subscale include throwing objects at others, removal of clothing at inappropriate times, and poking him/herself in the eye, respectively. Initial psychometrics for the scale indicate moderate inter-rater reliability, moderate to good test-retest reliability, and good internal consistency reliability (Matson \& Rivet, 2008). In a follow-up validity study, the $A S D-B P A$ was compared to the BPI-O1 and was found to have good validity (Matson \& Rivet, 2007).

Autism Spectrum Disorders-Behavior Problems for Children (ASD-BPC). The $A S D-B P C$ is the only comprehensive assessment of challenging behaviors for children with ASDs (Matson, Gonzalez et al., 2008). Similar to the $A S D-B P A$, this scale is part of a larger, comprehensive battery with its emphasis on children, which also includes the Autism Spectrum Disorders-Diagnosis for Children and Autism Spectrum Disorders-Comorbidity for Children. The scale contains 18 items, each of which are rated 0 (not different; no impairment), 1 (somewhat different; mild impairment), or 2 (very different; severe impairment) by informants. Results indicate that the items load onto two factors - externalizing and internalizing. Examples of items include smearing or playing with feces, playing with own saliva, and aggression toward others. Overall, initial psychometrics of the $A S D-B P C$ suggest fair to excellent inter-rater reliability and good to excellent test-retest reliability. Research to determine the validity of this scale is still underway.

Children's Scale of Hostility and Aggression: Reactive/Proactive (C-SHARP). Though the $C$ SHARP is not a comprehensive assessment of challenging behaviors in those with ASDs, it warrants mention given its concentration on those with developmental disabilities. The $C$-SHARP is a scale designed to measure 
aggression in children with developmental disabilities while also determining whether the aggressive behavior evinced is proactive or reactive (Farmer \& Aman, 2009). Proactive behavior has been previously defined as goal-oriented engagement in the behavior where an outcome is expected while reactive behavior has been defined as engagement in the behavior in response to being externally provoked (Dodge \& Coie, 1987). The $C$ SHARP contains 2 separate scales (i.e., problem and provocation scales) with 48 items each that make up 5 factors, which include verbal aggression, bullying, covert aggression, hostility, and physical aggression (Farmer \& Aman, 2009). The problem scale assesses whether or not the behavior has been a problem in the past month using a Likert scale of ratings 0 (does not happen) to 3 (severe or frequent). The provocation scale determines if the behavior is reactive or proactive with Likert ratings -2 (provoked; reactive) to 0 (neutral) to +2 (not provoked; proactive). Though research on this measure has just begun, the authors report strong inter-rater reliability and validity in a subsequent paper that has been submitted for publication (Farmer \& Aman, submitted for publication, as cited in Farmer \& Aman, 2009). Additionally, the development of a similar scale for adults known as the Adult Scale of Hostility and Aggression: Reactive/Proactive (A-SHARP) has been constructed with research regarding its development also having been submitted for publication (Matlock \& Aman, submitted for publication, as cited in Farmer \& Aman, 2009).

Baby and Infant Screen for Children with aUtIsm Traits (BISCUIT). The BISCUIT has been developed to target the identification of ASD, mainly autism and PDD-NOS, in children between 17 and 37 months of age (Matson, Wilkins, Sevin et al., 2009). This assessment battery is comprised of three parts aimed to screen for ASD, assess for comorbid psychopathology, and assess for challenging behaviors typically occurring in the ASD population. The BISCUIT is administered to the parent, guardian, or caregiver of the infant or toddler and lasts approximately twenty to thirty minutes. Each of the three parts of the BISCUIT uses a 3-point Likert scale with scores 0, 1, and 2 indicating no problem or impairment, mild problem or impairment, and severe problem or impairment, respectively. The BISCUIT-Part 3, which is the section related to challenging behaviors, contains 15 items, within which 3 factors have been identified (Matson, Boisjoli, Rojahn, \& Hess, 2009; Rojahn et al., 2009). These factors are aggressive/disruptive behaviors (e.g., physical 
aggression, property destruction, yelling, and disrobing), stereotypic behaviors (e.g., repetitive body movements, unusual object play, and repetitive vocalizations), and self-injurious behaviors. Overall, the authors report excellent internal reliability for each of the three parts of the measure with coefficients ranging from .91 to .97 (Matson, Wilkins, Sevin et al., 2009). 


\section{Purpose}

A substantial amount of research has found significant differences between the percentage of individuals with ASD who engage in challenging behaviors compared to those with ID alone and typically developing individuals (e.g., Baghdadli et al., 2003; Holden \& Gitlesen, 2006; MacDonald et al., 2007; Matson, Wilkins, \& Macken, 2009). To date, this literature has not extended past overall group differences to find significant differences in endorsement rates between specific ASD diagnoses, though similar research has been conducted within the ID population in reference to level of ID and endorsement rates of challenging behaviors (e.g., Allen, 2000; Tyrer et al., 2006). Even though challenging behaviors are not currently part of the criteria to be diagnosed with autism or PDD-NOS, they are prevalent in both populations making assessment crucial. Initial research has found that severity of autism (i.e., autism vs. PDD-NOS) may contribute to differences in rates of challenging behaviors although significant differences have not yet been investigated (Matson, Wilkins, \& Macken, 2009; Rojahn et al., 2009).

Given this information, identifying differences in endorsement rates between these two groups could potentially assist in differential diagnosis since PDD-NOS is often considered a less severe degree of autism. Additionally, due to the high prevalence of challenging behaviors in the ASD population and its referral rates for treatment, information is needed to accurately identify the rates and severity of these behaviors so that implementation of treatment can occur as well as research regarding treatments for the most prevalent behaviors. Therefore, this study looked at finding significant differences between groups in challenging behaviors overall as well as differences between groups on specific challenging behavior items.

Furthermore, significant differences between genders and the presence of challenging behaviors in the ASD population have not received much attention. Given that males are more likely to carry a diagnosis of an ASD, the possibility of these differences warrants attention. One behavior area that has received some attention is that of aggression. However, previous studies have found inconsistent results regarding the relationship between gender and aggressive/destructive behaviors with some research indicating that males tend to be more aggressive/destructive (McClintock et al., 2003) while others indicate no difference between genders (Murphy 
et al., 2009). Significant differences between genders in relation to stereotypic behaviors and self-injurious behaviors have not received much attention as of yet. Since gender difference results are inconsistent (i.e., aggressive/destructive behaviors) and lacking with respect to specific challenging behaviors (i.e., stereotypic behaviors and self-injurious behaviors), this study also focused on determining if significant differences are present between gender and the endorsement rates of problem behavior items within diagnostic groups (i.e., autism, PDD-NOS, atypically developing without an ASD diagnosis).

In conjunction with and building upon previous research, several outcomes were expected. First, based on a previous study using correlations (Rojahn et al., 2009), it was hypothesized that infants and toddlers with autism would exhibit significantly higher rates of challenging behaviors than those with PDD-NOS on the BISCUIT-Part 3 overall, as well as along each of the behavior items as demonstrated through a main effect. These results would demonstrate that severity of ASD influences the presence of challenging behaviors, despite its exclusion from the criteria for a diagnosis. Similar findings have been found by Matson, Wilkins, and Macken (2009) in children ages 2 through 17 with ASD, although differential diagnosis between autism and PDD-NOS was not incorporated in that specific study.

Additionally, it was hypothesized that main effects would show that those carrying diagnoses of PDDNOS would exhibit more challenging behaviors than the atypically developing without an ASD diagnosis group. All of these significant differences were also predicted to occur within the total BISCUIT-Part 3 score as well as along each of the behavior items. These hypotheses were based on the research outlined previously indicating that a higher percentage of individuals with ASDs demonstrate aggressive, stereotypic, and selfinjurious behaviors than those with ID alone.

Based on previous research indicating a possible relationship between gender and aggressive/destructive behaviors in those with ASDs (McClintock et al., 2003), it was also expected that males would evince significantly more aggressive/destructive behaviors than females. Although other current research debates this hypothesis (Murphy et al., 2009), gender differences have also been found in the typically developing population among aggressive/destructive behaviors (Alink et al., 2006; Lee et al., 2007). Therefore, both a main 
effect of gender and an interaction of gender and diagnostic group were expected. As of yet, very little research has focused on gender differences in regards to stereotypic and self-injurious behaviors within the ASD

population. Within the typically developing child population, no significant gender differences have been found in relation to stereotypic behavior (Harris, et al., 2008). As such, it was predicted that no significant gender differences would be found on the stereotypic behavior items within this study. Additionally, since McClintock et al. (2003) also found that there were no significant gender differences in relation to self-injurious behaviors, it was also predicted that there would be no significant gender differences on the self-injurious behavior items within this study. 


\section{Method}

\section{Participants}

Three hundred twenty-two infants and toddlers were selected for inclusion in this study from a database containing 1,509 infants and toddlers. The participants were recruited from EarlySteps and placed in one of six groups based on clinical diagnoses - autism, PDD-NOS, atypically developing without an ASD diagnosis - and divided further by gender. EarlySteps is Louisiana's Early Intervention System under the Individuals with Disabilities Education Act, Part C, which provides services to infants and toddlers and their families from birth to 36 months. Children qualify if they have a medical condition likely to result in a developmental delay, or have developmental delays. Diagnoses were made by a licensed psychologist, who was blind to BISCUIT scores, based on currently used methodologies including reference to the DSM-IV-TR criteria (APA, 2000), Modified Checklist for Autism in Toddlers scores (Robins, Fein, Barton, \& Green, 2001), and developmental profile scores obtained on the Battelle Developmental Inventory, Second Edition (Newborg, 2005). Interrater reliability of diagnoses was obtained by a second Ph.D. level psychologist for a subset of participants within the study $(n=42)$. The Ph.D. level psychologist had several years of experience assessing and treating children with developmental disabilities, and he utilized identical diagnostic methods as the licensed psychologist who initially assigned diagnoses. Interrater reliability for diagnoses was good with a kappa value of $.89, p=.000$.

Prior to selecting participants for inclusion, the original database was examined for missing values and errors in data entry. Any participants who were noted to have a necessary value either missing or entered incorrectly were removed. Additionally, any participants who were out of the designated age range for the measure were also excluded. As a result, 173 participants (11.46\%) were removed from the original database, which contained 1,509 infants and toddlers, prior to selecting participants. Next, since the database mimics the male to female ratio of ASDs in that there are significantly more males than females, the study population was chosen by selecting the maximum number of females from each diagnostic group while ensuring that no group was more than 1.5 times larger than any other so that statistical analyses could be computed while ensuring that assumptions of normality and homogeneity of variance were not violated (Leech, Barrett, \& Morgan, 2008). An 
equal number of males from each diagnostic group were then randomly selected as well based on this same rationale since gender was also an independent variable.

Demographic characteristics were collected on all participants. There were an equal number of males and females within each diagnostic group (i.e., autism, PDD-NOS, and atypically developing without an ASD diagnosis). All participants were between 17 and 36 months of age $(M=26.19 ; \mathrm{SD}=5.074)$. The mean age for the autism group was 26.57 months $(\mathrm{SD}=4.839)$ with an age range of 17 to 36 months. Within the autism group, $46.74 \%$ of the group participants were Caucasian, 46.74\% African American, 2.17\% Hispanic, and $4.35 \%$ other. The mean age for the PDD-NOS group was 26.14 months (SD $=5.036)$ with an age range of 17 to 35 months. Within the PDD-NOS group, 52.63\% of the group participants were Caucasian, $37.72 \%$ African American, $1.75 \%$ Hispanic, and $7.90 \%$ other. The mean age for the atypically developing without an ASD diagnosis group was 25.94 months $(\mathrm{SD}=5.313)$ with an age range of 17 to 35 months. Within the atypically developing without an ASD diagnosis group, 59.48\% of the group participants were Caucasian, 33.62\% African American, .86\% Hispanic, and 6.04\% other. Since gender also served as an independent variable, demographic characteristics for the study sample based on diagnostic group and gender are presented in Table 1.

Table 1

Demographic Characteristics per Diagnostic Group and Gender $(\mathrm{N}=322)$

\section{Diagnostic \\ Groups}

\begin{tabular}{|c|c|c|c|c|c|c|}
\hline $\begin{array}{l}\text { Demographic } \\
\text { Variables }\end{array}$ & $\begin{array}{l}\text { Males Autism } \\
\quad(\mathrm{n}=46)\end{array}$ & $\begin{array}{c}\text { Females } \\
\text { Autism } \\
(\mathrm{n}=46)\end{array}$ & $\begin{array}{c}\text { Males PDD- } \\
\text { NOS } \\
(n=57)\end{array}$ & $\begin{array}{l}\text { Females } \\
\text { PDD- } \\
\text { NOS } \\
(\mathrm{n}=57)\end{array}$ & $\begin{array}{c}\text { Males } \\
\text { Atypically } \\
\text { Developing } \\
\text { without an } \\
\text { ASD } \\
\text { Diagnosis } \\
(\mathrm{n}=58)\end{array}$ & $\begin{array}{c}\text { Females } \\
\text { Atypically } \\
\text { Developing } \\
\text { without an } \\
\text { ASD } \\
\text { Diagnosis } \\
(\mathrm{n}=58)\end{array}$ \\
\hline $\begin{array}{l}\text { Age (in months), } \\
\text { Mean (SD) }\end{array}$ & $25.76(5.425)$ & $\begin{array}{c}27.37 \\
(4.074)\end{array}$ & $\begin{array}{c}26.00 \\
(4.822)\end{array}$ & $\begin{array}{l}26.28 \\
(5.281)\end{array}$ & $\begin{array}{c}25.52 \\
(5.144)\end{array}$ & $\begin{array}{c}26.36 \\
(5.489)\end{array}$ \\
\hline $\begin{array}{l}\text { Ethnicity, \% } \\
\text { Caucasian }\end{array}$ & $43.48 \%$ & $50.00 \%$ & $50.88 \%$ & $54.39 \%$ & $58.62 \%$ & $60.34 \%$ \\
\hline African American & $47.83 \%$ & $45.66 \%$ & $35.09 \%$ & $40.35 \%$ & $31.04 \%$ & $36.21 \%$ \\
\hline Hispanic & $2.17 \%$ & $2.17 \%$ & $3.51 \%$ & $0.00 \%$ & $1.72 \%$ & $0.00 \%$ \\
\hline Other & $6.52 \%$ & $2.17 \%$ & $10.52 \%$ & $5.26 \%$ & $8.62 \%$ & $3.45 \%$ \\
\hline
\end{tabular}




\section{Measures}

The previously described BISCUIT-Part 3 comprised the dependent variables for this study. As was discussed earlier, the BISCUIT-Part 3 is a section from the comprehensive BISCUIT measure focusing on the endorsement rates of challenging behaviors of infants and toddlers with an ASD (Matson, Wilkins, Sevin et al., 2009). It contains 15 items along 3 factors - aggressive/disruptive behaviors, stereotypic behaviors, and selfinjurious behaviors (Matson, Boisjoli et al., 2009). Each item is rated using a 3-point Likert scale with scores 0, 1, and 2 indicating no problem or impairment, mild problem or impairment, and severe problem or impairment, respectively. The authors report an excellent internal reliability coefficient of .91 for this portion of the measure (Matson, Wilkins, Sevin et al., 2009).

\section{Procedure}

EarlySteps participants received the comprehensive assessment battery typically offered by the program with the addition of the BISCUIT, which was administered to the parent/guardian of the child by a trained interviewer employed by the state of Louisiana who was blind to BISCUIT scores. All interviewers held a minimum of a bachelor's degree and attended training on BISCUIT development, administration, and interpretation in addition to an overview of ASD in general. Diagnoses were made based on currently used methodologies as described previously. Although this study only analyzed endorsements on Part-3 of the BISCUIT, the measure was administered in its entirety in order to avoid any confounds that might emerge due to altering the method of administration. The studies contained within this defense have been previously approved by the Louisiana State University Institutional Review Board and Louisiana's Office for Citizens with Developmental Disabilities. Furthermore, all participants are the parents or legal guardians of the individual being assessed and have supplied informed consent for participation.

\section{Research Design}

A priori analyses were run to ensure that the groups did not significantly differ with respect to demographic variables (i.e., gender, ethnicity, and age). Chi-square analyses revealed that there were no significant differences in gender or ethnicity between groups. A one-way between-subjects Analysis of 
Variance (ANOVA) indicated that there were also no significant differences in age between groups. Next, a Kolmogorov-Smirnov test was employed to test for normality within the sample distribution. Although the sample significantly differed from that of a normal distribution, small deviations from normality within a large sample often result in significance when using this test (Field, 2005). Additionally, a growing amount of literature has suggested that deviating from normality is an acceptable assumption violation when using a large sample size (Field, 2005; Glass, Peckham, \& Sanders, 1972; Harwell, Rubinstein, Hayes, \& Olds, 1992; Lix, Keselman, \& Keselman, 1996; Lunney, 1970). As such, it was decided that the robust nature of parametric statistics would prevail despite the violation of normality when using a sample of 322 participants. Furthermore, homogeneity of variance can be assumed by using equal sample sizes within each of the diagnostic groups (Field, 2005). Although this was not accomplished with precision within this sample, this rule also holds when no group is more than 1.5 times larger than any other (Leech et al., 2008). As such, homogeneity of variance could be assumed for this sample.

Three between-subjects Multivariate Analyses of Variance (MANOVAs) were conducted with diagnostic group (i.e., autism, PDD-NOS, and atypically developing without an ASD diagnosis) and gender as the independent variables and the 15 problem behavior items serving as the dependent variables. The 15 problem behavior items were distributed among the three MANOVAs according to their previously derived factor membership (i.e., aggressive/disruptive behaviors, stereotypic behaviors, and self-injurious behaviors) (Matson, Boisjoli, et al., 2009; Rojahn et al., 2009). Significant results on each of the MANOVAs were followed up with ANOVAs. The alpha level of .05 for each ANOVA was divided by the number of ANOVAs computed simultaneously so as to control for family-wise error (Field, 2005). Subsequently, significant results on each of the ANOVAs were followed up with Bonferroni post hoc tests to identify significant differences while controlling for the inflation of family-wise error (Field, 2005). A priori power analyses were conducted in order to determine the sample size required for this study using the statistical program, G*Power 3 (Faul, Erdfelder, Lang, \& Buchner, 2007). For the MANOVAs, the alpha level had been set at .05 while the power had been set at .80. These levels are considered to be ideal for studies in the behavioral sciences (Hinkle, Wiersma, 
$\&$ Jurs, 2003). Additionally, a medium effect size of $f=.25$ (Cohen, 1992) was used for this study as a medium effect size has been determined to be the largest effect size appropriate for studies in the behavioral sciences (Cohen, 1988). Results indicated that for the MANOVA examining aggressive/destructive behaviors, a total sample size of 36 was needed. A total sample size of 30 was needed for the MANOVA examining stereotypic behaviors and a total sample size of 42 for the self-injurious behaviors.

Next, a between-subjects Analysis of Variance (ANOVA) was conducted with diagnostic group (i.e., autism, PDD-NOS, and atypically developing without an ASD diagnosis) and gender as the independent variables and total score on the BISCUIT-Part 3 as the dependent variable. Total score on the BISCUIT-Part 3 was computed by summing scores on the 15 problem behavior items for each participant. Significant results on this test were also followed up with Bonferroni post hoc tests in order to identify significant differences while controlling for the inflation of family-wise error (Field, 2005). Once again, an a priori analysis was conducted to determine the required sample size needed when using an alpha level of .05 , power of .80 , and medium effect size of .25. Results indicated that a total sample size of 211 participants was needed. 


\section{Results}

First, descriptive statistics were computed in order to determine the percent item endorsement within each diagnostic group as well as within each gender group according to diagnosis. These percentages are presented in Table 2.

Table 2

Percent Item Endorsement per Group

\begin{tabular}{|c|c|c|c|c|c|c|c|c|c|}
\hline \multirow{2}{*}{$\begin{array}{l}\text { Problem } \\
\text { Behavior }\end{array}$} & \multicolumn{9}{|c|}{ Group } \\
\hline & $\begin{array}{l}\text { Autism } \\
\text { Total }\end{array}$ & $\begin{array}{l}\text { Autism } \\
\text { Male }\end{array}$ & $\begin{array}{l}\text { Autism } \\
\text { Female }\end{array}$ & $\begin{array}{l}\text { PDD- } \\
\text { NOS } \\
\text { Total }\end{array}$ & $\begin{array}{l}\text { PDD- } \\
\text { NOS } \\
\text { Male }\end{array}$ & $\begin{array}{l}\text { PDD- } \\
\text { NOS } \\
\text { Female }\end{array}$ & $\begin{array}{l}\text { Atypically } \\
\text { Developing } \\
\text { Total }\end{array}$ & $\begin{array}{l}\text { Atypically } \\
\text { Developing } \\
\text { Male }\end{array}$ & $\begin{array}{l}\text { Atypically } \\
\text { Developing } \\
\text { Female }\end{array}$ \\
\hline $\begin{array}{l}\text { Poking } \\
\text { him/her self in } \\
\text { the eye }\end{array}$ & $20.7 \%$ & $19.6 \%$ & $21.7 \%$ & $6.1 \%$ & $8.8 \%$ & $3.5 \%$ & $0.0 \%$ & $0.0 \%$ & $0.0 \%$ \\
\hline $\begin{array}{l}\text { Harming self } \\
\text { by hitting, } \\
\text { pinching, } \\
\text { scratching, } \\
\text { etc. }\end{array}$ & $37.0 \%$ & $34.8 \%$ & $39.1 \%$ & $15.8 \%$ & $32.6 \%$ & $14.0 \%$ & $6.9 \%$ & $6.9 \%$ & $6.9 \%$ \\
\hline $\begin{array}{l}\text { Kicking } \\
\text { objects }\end{array}$ & $37.0 \%$ & $47.8 \%$ & $26.1 \%$ & $23.7 \%$ & $24.6 \%$ & $22.8 \%$ & $5.2 \%$ & $5.2 \%$ & $5.2 \%$ \\
\hline $\begin{array}{l}\text { Removal of } \\
\text { clothing at } \\
\text { inappropriate } \\
\text { times }\end{array}$ & $26.1 \%$ & $28.3 \%$ & $23.9 \%$ & $18.4 \%$ & $15.8 \%$ & $21.1 \%$ & $4.3 \%$ & $3.4 \%$ & $5.2 \%$ \\
\hline $\begin{array}{l}\text { Unusual play } \\
\text { with objects }\end{array}$ & $41.3 \%$ & $50.0 \%$ & $32.6 \%$ & $12.3 \%$ & $17.5 \%$ & $7.0 \%$ & $0.9 \%$ & $1.7 \%$ & $0.0 \%$ \\
\hline $\begin{array}{l}\text { Playing with } \\
\text { own saliva }\end{array}$ & $15.2 \%$ & $21.7 \%$ & $8.7 \%$ & $8.8 \%$ & $3.5 \%$ & $14.0 \%$ & $2.6 \%$ & $3.4 \%$ & $1.7 \%$ \\
\hline $\begin{array}{l}\text { Throwing } \\
\text { objects at } \\
\text { others }\end{array}$ & $50.0 \%$ & $52.2 \%$ & $47.8 \%$ & $32.5 \%$ & $33.3 \%$ & $31.6 \%$ & $12.9 \%$ & $19.0 \%$ & $6.9 \%$ \\
\hline $\begin{array}{l}\text { Banging on } \\
\text { objects with } \\
\text { hand }\end{array}$ & $48.9 \%$ & $54.3 \%$ & $43.5 \%$ & $24.6 \%$ & $21.1 \%$ & $28.1 \%$ & $8.6 \%$ & $12.1 \%$ & $5.2 \%$ \\
\hline $\begin{array}{l}\text { Leaving the } \\
\text { supervision of } \\
\text { caregiver } \\
\text { without } \\
\text { permission }\end{array}$ & $35.9 \%$ & $34.8 \%$ & $37.0 \%$ & $22.8 \%$ & $22.8 \%$ & $22.8 \%$ & $4.3 \%$ & $5.2 \%$ & $3.4 \%$ \\
\hline $\begin{array}{l}\text { Aggression } \\
\text { toward others }\end{array}$ & $44.6 \%$ & $45.7 \%$ & $43.5 \%$ & $27.2 \%$ & $24.6 \%$ & $29.8 \%$ & $12.1 \%$ & $15.5 \%$ & $8.6 \%$ \\
\hline $\begin{array}{l}\text { Pulling others' } \\
\text { hair }\end{array}$ & $34.8 \%$ & $30.4 \%$ & $39.1 \%$ & $28.1 \%$ & $26.3 \%$ & $29.8 \%$ & $8.6 \%$ & $12.1 \%$ & $5.2 \%$ \\
\hline $\begin{array}{l}\text { Yelling or } \\
\text { shouting at } \\
\text { others }\end{array}$ & $29.3 \%$ & $30.4 \%$ & $28.3 \%$ & $18.4 \%$ & $19.3 \%$ & $17.5 \%$ & $8.6 \%$ & $10.3 \%$ & $6.9 \%$ \\
\hline $\begin{array}{l}\text { Property } \\
\text { desetruction }\end{array}$ & $35.9 \%$ & $39.1 \%$ & $32.6 \%$ & $18.4 \%$ & $21.1 \%$ & $15.8 \%$ & $7.8 \%$ & $5.2 \%$ & $10.3 \%$ \\
\hline $\begin{array}{l}\text { Repeated and } \\
\text { unusual } \\
\text { vocalizations }\end{array}$ & $34.8 \%$ & $34.8 \%$ & $34.8 \%$ & $14.0 \%$ & $15.8 \%$ & $12.3 \%$ & $2.6 \%$ & $3.4 \%$ & $1.7 \%$ \\
\hline $\begin{array}{l}\text { Repeated and } \\
\text { unusual body } \\
\text { movements }\end{array}$ & $35.7 \%$ & $45.7 \%$ & $35.7 \%$ & $13.2 \%$ & $17.5 \%$ & $8.8 \%$ & $1.7 \%$ & $3.4 \%$ & $0.0 \%$ \\
\hline Total & $85.9 \%$ & $80.4 \%$ & $91.3 \%$ & $66.7 \%$ & $68.4 \%$ & $64.9 \%$ & $25.0 \%$ & $29.3 \%$ & $20.7 \%$ \\
\hline
\end{tabular}


Next, a MANOVA was conducted with diagnostic group and gender as the independent variables and the 10 problem behavior items along the aggressive/destructive behaviors subscale serving as the dependent variables. The main effect for diagnostic group was significant, Wilks' $\Lambda=.782, F(20,614)=4.010, p=.000$. The main effect for gender was not significant, Wilks' $\Lambda=.966, F(10,307)=1.074, p=.382$. The interaction of diagnostic group and gender was also not significant, Wilks' $\Lambda=.910, F(20,614)=1.477, p=.082$. The significant main effect of diagnostic group was followed with a series of ANOVAs for each of the 10 aggressive/destructive behavior items using an alpha of $.05 / 10=.005$ in order to control for inflation of familywise error. Additionally, all significant ANOVAs were in turn followed with Bonferroni post hoc tests, which also controlled for inflation of family-wise error. Results from the Bonferroni post hoc tests for each aggressive/destructive behavior item with a significant ANOVA are presented in Table 3. Within the table, pvalues have been adjusted so that all results can be interpreted at the .05 level after Bonferroni adjustments have been made.

There was a significant main effect of diagnostic group on kicking objects, $F(2,567)=19.663, p=$ .000. A Bonferroni post hoc test was run. The autism group $(M=.5870)$ significantly differed from the PDDNOS group $(M=.3333)$ and from the atypically developing without an ASD diagnosis group $(M=.0603)$. Additionally, the PDD-NOS group $(M=.3333)$ also significantly differed from the atypically developing without an ASD group $(M=.0603)$.

For removal of clothing at inappropriate times there was a significant main effect of diagnostic group, $F$ $(2,316)=8.370, p=.000$. A Bonferroni post hoc test was run. The autism group $(M=.3804)$ did not significantly differ from the PDD-NOS group $(M=.2807)$, but did significantly differ from the atypically developing without an ASD diagnosis group $(M=.0690)$. Additionally, the PDD-NOS group $(M=.2807)$ significantly differed from the atypically developing without an ASD group $(M=.0690)$.

For playing with own saliva the main effect for diagnostic group was not significant, $F(2,316)=3.926$, $p=.021$. Therefore, no follow-up post hoc tests were run. 
For throwing objects at others there was a significant main effect of diagnostic group, $F(2,316)=$ $21.319, p=.000$. A Bonferroni post hoc test was run. The autism group $(M=.7717)$ significantly differed from the PDD-NOS group $(M=.4649)$ and from the atypically developing without an ASD diagnosis group $(M=$ .1552). Additionally, the PDD-NOS group $(M=.4649)$ also significantly differed from the atypically developing without an ASD group $(M=.1552)$.

For banging on objects with hand there was a significant main effect of diagnostic group, $F(2,316)=$ $23.148, p=.000$. A Bonferroni post hoc test was run. The autism group $(M=.6957)$ significantly differed from the PDD-NOS group $(M=.3596)$ and from the atypically developing without an ASD diagnosis group $(M=$ .1034). Additionally, the PDD-NOS group $(M=.3596)$ also significantly differed from the atypically developing without an ASD group $(M=.1034)$.

There was a significant main effect of diagnostic group on leaving the supervision of caregiver without permission, $F(2,316)=19.640, p=.000$. A Bonferroni post hoc test was run. The autism group $(M=.6196)$ significantly differed from the PDD-NOS group $(M=.3333)$ and from the atypically developing without an ASD diagnosis group $(M=.0603)$. Additionally, the PDD-NOS group $(M=.3333)$ also significantly differed from the atypically developing without an ASD group $(M=.0603)$.

For aggression toward others there was a significant main effect of diagnostic group, $F(2,316)=$ $14.093, p=.000$. A Bonferroni post hoc test was run. The autism group $(M=.6630)$ significantly differed from the PDD-NOS group $(M=.4035)$ and from the atypically developing without an ASD diagnosis group $(M=$ .1638). Additionally, the PDD-NOS group $(M=.4035)$ also significantly differed from the atypically developing without an ASD group $(M=.1638)$.

For pulling others' hair there was a significant main effect of diagnostic group, $F(2,316)=10.755, p=$ .000. A Bonferroni post hoc test was run. The autism group $(M=.5109)$ did not significantly differ from the PDD-NOS group $(M=.4298)$, but did significantly differ from the atypically developing without an ASD diagnosis group $(M=.1207)$. Additionally, the PDD-NOS group $(M=.4298)$ significantly differed from the atypically developing without an ASD group $(M=.1207)$. 
For yelling or shouting at others there was a significant main effect of diagnostic group, $F(2,316)=$ 8.862, $p=.000$. A Bonferroni post hoc test was run. The autism group $(M=.5000)$ significantly differed from the PDD-NOS group $(M=.2719)$ and from the atypically developing without an ASD diagnosis group $(M=$ .1293). However, the PDD-NOS group $(M=.2719)$ did not significantly differ from the atypically developing without an ASD group $(M=.1293)$.

For property destruction there was a significant main effect of diagnostic group, $F(2,567)=12.915, p=$ .000. A Bonferroni post hoc test was run. The autism group $(M=.5109)$ significantly differed from the PDDNOS group $(M=.2807)$ and from the atypically developing without an ASD diagnosis group $(M=.0948)$. Additionally, the PDD-NOS group $(M=.2807)$ also significantly differed from the atypically developing without an ASD group $(M=.0948)$.

Next, a MANOVA with diagnostic group and gender as the independent variables and the three problem behavior items along the stereotypic behaviors subscale as the dependent variables was conducted. The main effect for diagnostic group was significant, Wilks' $\Lambda=.706, F(6,628)=19.898, p=.000$. The main effect for gender was not significant, Wilks' $\Lambda=.981, F(3,314)=2.037, p=.109$. The interaction of diagnostic group and gender was also not significant, Wilks' $\Lambda=.986, F(6,628)=.727, p=.628$. The significant main effect of diagnostic group was followed with a series of ANOVAs for each of the three stereotypic behavior items using an alpha of $.05 / 3=.17$ to control for inflation of family-wise error. Subsequently, all significant ANOVAs were followed with Bonferroni post hoc tests, which controlled for inflation of family-wise error as well. Results for the Bonferroni post hoc tests for each stereotypic behavior item are presented in Table 4. Within the table, pvalues have been adjusted so that all results can be interpreted at the .05 level after Bonferroni adjustments have been made.

For unusual play with objects there was a significant main effect of diagnostic group, $F(2,316)=$ $37.878, p=.000$. A Bonferroni post hoc test was run. The autism group $(M=.5978)$ significantly differed from the PDD-NOS group $(M=.1579)$ and from the atypically developing without an ASD diagnosis group $(M=$ 
Table 3

Bonferroni Post Hoc Tests per Diagnostic Group - Aggressive/Destructive Behaviors

\begin{tabular}{|c|c|c|c|c|}
\hline $\begin{array}{l}\text { Problem } \\
\text { Behavior }\end{array}$ & $\begin{array}{l}\text { Diagnostic } \\
\text { Group }\end{array}$ & $\begin{array}{l}\text { Comparison } \\
\text { Diagnostic } \\
\text { Group } \\
\end{array}$ & $\begin{array}{l}\text { Mean } \\
\text { Difference }\end{array}$ & P-value \\
\hline \multirow[t]{3}{*}{ Kicking objects } & Autism & PDD-NOS & .254 & $.009 *$ \\
\hline & Autism & $\begin{array}{l}\text { Atypically } \\
\text { Developing } \\
\text { without an ASD } \\
\text { Diagnosis }\end{array}$ & .527 & $.000 *$ \\
\hline & PDD-NOS & $\begin{array}{l}\text { Atypically } \\
\text { Developing } \\
\text { without an ASD } \\
\text { Diagnosis }\end{array}$ & .273 & $.002 *$ \\
\hline \multirow{3}{*}{$\begin{array}{l}\text { Removal of } \\
\text { clothing at } \\
\text { inappropriate } \\
\text { times }\end{array}$} & Autism & PDD-NOS & .100 & .631 \\
\hline & Autism & $\begin{array}{l}\text { Atypically } \\
\text { Developing } \\
\text { without an ASD } \\
\text { Diagnosis }\end{array}$ & .311 & $.000 *$ \\
\hline & PDD-NOS & $\begin{array}{l}\text { Atypically } \\
\text { Developing } \\
\text { without an ASD } \\
\text { Diagnosis }\end{array}$ & .212 & $.015^{*}$ \\
\hline \multirow{3}{*}{$\begin{array}{l}\text { Throwing } \\
\text { objects at others }\end{array}$} & Autism & PDD-NOS & .307 & $.004 *$ \\
\hline & Autism & $\begin{array}{l}\text { Atypically } \\
\text { Developing } \\
\text { without an ASD } \\
\text { Diagnosis }\end{array}$ & .617 & $.000 *$ \\
\hline & PDD-NOS & $\begin{array}{l}\text { Atypically } \\
\text { Developing } \\
\text { without an ASD } \\
\text { Diagnosis }\end{array}$ & .310 & $.002 *$ \\
\hline \multirow{3}{*}{$\begin{array}{l}\text { Banging on } \\
\text { objects with } \\
\text { hand }\end{array}$} & Autism & PDD-NOS & .336 & $.000 *$ \\
\hline & Autism & $\begin{array}{l}\text { Atypically } \\
\text { Developing } \\
\text { without an ASD } \\
\text { Diagnosis }\end{array}$ & .592 & $.000 *$ \\
\hline & PDD-NOS & $\begin{array}{l}\text { Atypically } \\
\text { Developing } \\
\text { without an ASD } \\
\text { Diagnosis }\end{array}$ & .256 & $.006^{*}$ \\
\hline
\end{tabular}




\begin{tabular}{|c|c|c|c|c|}
\hline \multirow{3}{*}{$\begin{array}{l}\text { Leaving the } \\
\text { supervision of } \\
\text { caregiver } \\
\text { without } \\
\text { permission }\end{array}$} & Autism & PDD-NOS & .286 & $.005^{*}$ \\
\hline & Autism & $\begin{array}{l}\text { Atypically } \\
\text { Developing } \\
\text { without an ASD } \\
\text { Diagnosis }\end{array}$ & .559 & $.000^{*}$ \\
\hline & PDD-NOS & $\begin{array}{l}\text { Atypically } \\
\text { Developing } \\
\text { without an ASD } \\
\text { Diagnosis }\end{array}$ & .273 & $.004 *$ \\
\hline \multirow{3}{*}{$\begin{array}{l}\text { Aggression } \\
\text { toward others }\end{array}$} & Autism & PDD-NOS & .260 & $.019^{*}$ \\
\hline & Autism & $\begin{array}{l}\text { Atypically } \\
\text { Developing } \\
\text { without an ASD } \\
\text { Diagnosis }\end{array}$ & .499 & $.000^{*}$ \\
\hline & PDD-NOS & $\begin{array}{l}\text { Atypically } \\
\text { Developing } \\
\text { without an ASD } \\
\text { Diagnosis }\end{array}$ & .240 & $.022^{*}$ \\
\hline \multirow{3}{*}{$\begin{array}{l}\text { Pulling others' } \\
\text { hair }\end{array}$} & Autism & PDD-NOS & .081 & 1.000 \\
\hline & Autism & $\begin{array}{l}\text { Atypically } \\
\text { Developing } \\
\text { without an ASD } \\
\text { Diagnosis }\end{array}$ & .390 & $.000^{*}$ \\
\hline & PDD-NOS & $\begin{array}{l}\text { Atypically } \\
\text { Developing } \\
\text { without an ASD } \\
\text { Diagnosis }\end{array}$ & .309 & $.001^{*}$ \\
\hline \multirow{3}{*}{$\begin{array}{l}\text { Yelling or } \\
\text { shouting at } \\
\text { others }\end{array}$} & Autism & PDD-NOS & .228 & $.032^{*}$ \\
\hline & Autism & $\begin{array}{l}\text { Atypically } \\
\text { Developing } \\
\text { without an ASD } \\
\text { Diagnosis }\end{array}$ & .371 & $.000^{*}$ \\
\hline & PDD-NOS & $\begin{array}{l}\text { Atypically } \\
\text { Developing } \\
\text { without an ASD } \\
\text { Diagnosis }\end{array}$ & .143 & .264 \\
\hline
\end{tabular}




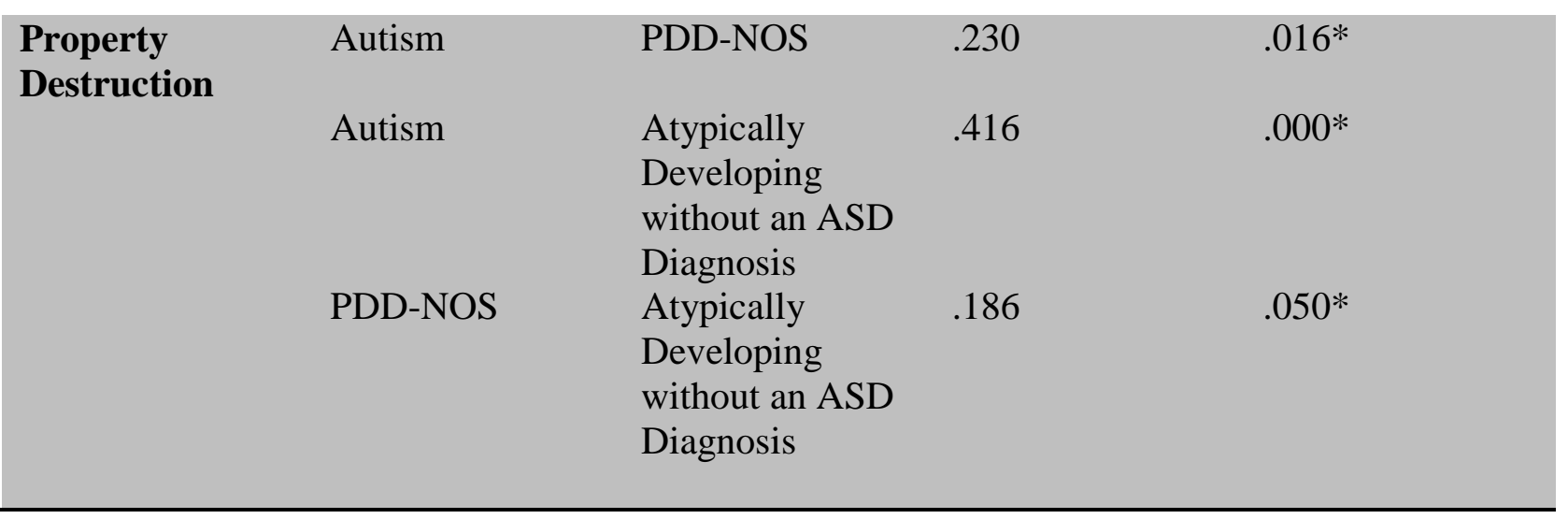

.0086). However, the PDD-NOS group $(M=.1579)$ did not significantly differ from the atypically developing without an ASD group $(M=.0086)$.

For repeated and unusual vocalizations there was a significant main effect of diagnostic group, $F$ (2, $316)=23.387, p=.000$. A Bonferroni post hoc test was run. The autism group $(M=.5761)$ significantly differed from the PDD-NOS group $(M=.2105)$ and from the atypically developing without an ASD diagnosis group $(M=.0259)$. Additionally, the PDD-NOS group $(M=.2105)$ also significantly differed from the atypically developing without an ASD group $(M=.0259)$.

For repeated and unusual body movements there was a significant main effect of diagnostic group, $F(2$, $316)=40.982, p=.000$. A Bonferroni post hoc test was run. The autism group $(M=.7065)$ significantly differed from the PDD-NOS group $(M=.1930)$ and from the atypically developing without an ASD diagnosis group $(M=.0172)$. However, the PDD-NOS group $(M=.1930)$ did not significantly differ from the atypically developing without an ASD group $(M=.0172)$.

Another MANOVA was run with diagnostic group and gender as the independent variables and the two problem behavior items along the self-injurious behaviors subscale as the dependent variables. The main effect for diagnostic group was significant, Wilks' $\Lambda=.867, F(4,630)=11.686, p=.000$. The main effect for gender was not significant, Wilks' $\Lambda=.998, F(2,315)=.259, p=.772$. The interaction of diagnostic group and gender was also not significant, Wilks' $\Lambda=.999, F(4,630)=.095, p=.984$. The significant main effect of diagnostic group was subsequently followed with two ANOVAs for each self-injurious behavior item using an alpha of 
Table 4

Bonferroni Post Hoc Tests per Diagnostic Group - Stereotypic Behaviors

\begin{tabular}{|c|c|c|c|c|}
\hline $\begin{array}{l}\text { Problem } \\
\text { Behavior }\end{array}$ & $\begin{array}{l}\text { Diagnostic } \\
\text { Group }\end{array}$ & $\begin{array}{l}\text { Comparison } \\
\text { Diagnostic } \\
\text { Group }\end{array}$ & $\begin{array}{l}\text { Mean } \\
\text { Difference }\end{array}$ & P-value \\
\hline \multirow{3}{*}{$\begin{array}{l}\text { Unusual play } \\
\text { with objects }\end{array}$} & Autism & PDD-NOS & .440 & $.000^{*}$ \\
\hline & Autism & $\begin{array}{l}\text { Atypically } \\
\text { Developing } \\
\text { without an ASD } \\
\text { Diagnosis }\end{array}$ & .589 & $.000 *$ \\
\hline & PDD-NOS & $\begin{array}{l}\text { Atypically } \\
\text { Developing } \\
\text { without an ASD } \\
\text { Diagnosis }\end{array}$ & .149 & .070 \\
\hline \multirow{3}{*}{$\begin{array}{l}\text { Repeated and } \\
\text { unusual } \\
\text { vocalizations }\end{array}$} & Autism & PDD-NOS & .366 & $.000 *$ \\
\hline & Autism & $\begin{array}{l}\text { Atypically } \\
\text { Developing } \\
\text { without an ASD } \\
\text { Diagnosis }\end{array}$ & .550 & $.000^{*}$ \\
\hline & PDD-NOS & $\begin{array}{l}\text { Atypically } \\
\text { Developing } \\
\text { without an ASD } \\
\text { Diagnosis }\end{array}$ & .185 & $.043 *$ \\
\hline \multirow{3}{*}{$\begin{array}{l}\text { Repeated and } \\
\text { unusual body } \\
\text { movements }\end{array}$} & Autism & PDD-NOS & .514 & $.000 *$ \\
\hline & Autism & $\begin{array}{l}\text { Atypically } \\
\text { Developing } \\
\text { without an ASD } \\
\text { Diagnosis }\end{array}$ & .689 & $.000^{*}$ \\
\hline & PDD-NOS & $\begin{array}{l}\text { Atypically } \\
\text { Developing } \\
\text { without an ASD } \\
\text { Diagnosis }\end{array}$ & .176 & .053 \\
\hline
\end{tabular}

$.05 / 2=.025$ in order to control for inflation of family-wise error. Next, Bonferroni post hoc tests were

conducted on significant ANOVAs, which controlled for inflation of family-wise error as well. Results for the

Bonferroni post hoc tests for each self-injurious behavior item are presented in Table 5. Within the table, p-

values have been adjusted so that all results can be interpreted at the .05 level after Bonferroni adjustments have been made. 
For poking him/her self in the eye there was a significant main effect of diagnostic group, $F(2,316)=$ $13.016, p=.000$. A Bonferroni post hoc test was run. The autism group $(M=.2826)$ significantly differed from the PDD-NOS group $(M=.0965)$ and from the atypically developing without an ASD diagnosis group $(M=$ .0000). However, the PDD-NOS group $(M=.0965)$ did not significantly differ from the atypically developing without an ASD group $(M=.0000)$.

For harming self by hitting, pinching, scratching, etcetera there was a significant main effect of diagnostic group, $F(2,316)=17.264, p=.000$. A Bonferroni post hoc test was run. The autism group $(M=$ $.5652)$ significantly differed from the PDD-NOS group $(M=.2368)$ and from the atypically developing without an ASD diagnosis group $(M=.0862)$. However, the PDD-NOS group $(M=.2368)$ did not significantly differ from the atypically developing without an ASD group $(M=.0862)$.

Following all MANOVAs and their respective ANOVAs and Bonferroni post hoc tests, a test for significance of a proportion was computed for all 15 problem behavior items. The two-tailed z-test showed that the observed order proportion (1.000) was significantly different from the expected order proportion $(.167), \mathrm{z}=$ 8.68, $p<.05$. Plots detailing the trends of each challenging behavior are presented in Figures 1 through 15 in Appendix B.

Finally, a between-subjects ANOVA was computed with diagnostic group and gender as the independent variables and the total score on the BISCUIT-Part 3 problem behavior items as the dependent variable. The main effect for diagnostic group was significant, $F(2,316)=49.419, p=.000$. The main effect for gender was not significant, $F(1,316)=1.624, p=.204$. The interaction of diagnostic group and gender was also not significant, $F(2,316)=.522, p=.594$. The significant main effect of diagnostic group was followed with Bonferroni post hoc tests. A Bonferroni post hoc test found that the autism group $(M=8.1739)$ significantly differed from the PDD-NOS group $(M=4.1842)$ and from the atypically developing without an ASD diagnosis group $(M=1.1379)$. Additionally, the PDD-NOS group $(M=4.1842)$ also significantly differed from the atypically developing without an ASD group $(M=1.1379)$. 
Table 5

Bonferroni Post Hoc Tests per Diagnostic Group - Self-Injurious Behaviors

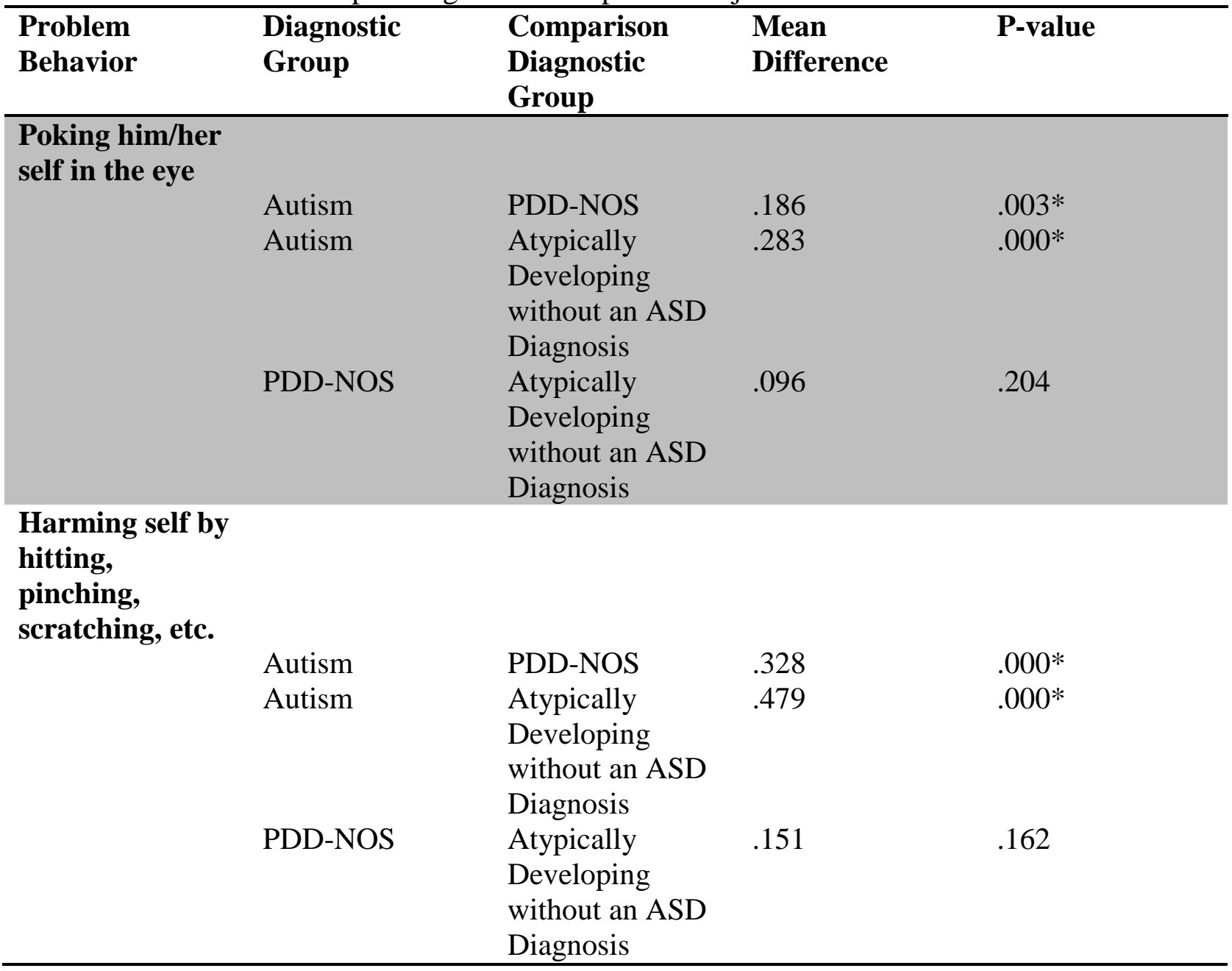




\section{Discussion}

Despite challenging behaviors not currently being incorporated into the diagnostic criteria for ASDs, the research literature continues to flourish with results indicating that challenging behaviors are not only present within this population, but are also very common (Matson \& Nebel-Schwalm, 2007; Matson, Wilkins, \& Macken, 2009; Mudford et al., 2008). Currently, the research literature provides evidence that individuals with ASD engage in significantly more challenging behaviors than their same-aged peers who have ID or are typically developing (Baghdadli et al., 2003; Holden \& Gitlesen, 2006; MacDonald et al., 2007; Matson, Wilkins, \& Macken, 2009). However, it remains unknown whether or not there are significant differences in the rates of challenging behaviors between individuals with different ASD diagnoses. Therefore, the purpose of this study was to determine if there are significant differences in the endorsement rates of challenging behaviors between groups of infants and toddlers with autism, PDD-NOS, and atypical development without an ASD. Additionally, as gender differences in relation to challenging behaviors have seldom been studied within the ASD population, this study also explored the possibility of such differences.

These data support the hypothesis that individuals with autism endorse significantly greater amounts of challenging behaviors than individuals with PDD-NOS. Of the 15 challenging behaviors assessed, the autism group had significantly higher endorsements on the majority of aggressive/destructive behavior items (i.e., kicking objects, throwing objects at others, banging on objects with hand, leaving the supervision of caregiver without permission, aggression toward others, property destruction, and yelling or shouting at others), all of the stereotypic behaviors (i.e., unusual play with objects, repeated and unusual vocalizations, and repeated and unusual body movements), and all of the self-injurious behaviors (i.e., poking him/her self in the eye and harming self). Therefore, it is apparent that the autism group displays greater behavioral deficits with respect to these items in relation to the PDD-NOS group. However, it is notable that the autism and PDD-NOS groups did not significantly differ in their endorsements on three of the aggressive/destructive behavior items - removal of clothing at inappropriate times, pulling others' hair, and playing with own saliva. Since stereotypic and selfinjurious behaviors are embedded within the diagnostic criteria for ASD through the third criterion of repetitive 
and restricted interests and behaviors (APA, 2000), it appears appropriate that these items would be the most likely to differentiate between these two diagnostic categories. This is especially true when viewing PDD-NOS as a less severe degree of autism.

In relation to the next hypothesis stating the PDD-NOS group would endorse significantly more problem behaviors than the atypically developing without an ASD group, there was somewhat less support. The PDDNOS group was found to have greater endorsements than the atypically developing without an ASD group on most of the aggressive/destructive behavior items (i.e., kicking objects, removal of clothing at inappropriate times, throwing objects at others, banging on objects with hand, leaving the supervision of caregiver without permission, aggression toward others, pulling others' hair, property destruction), but only had greater endorsements on one stereotypic behavior (i.e., repeated and unusual vocalizations) and on no self-injurious behaviors. Although these results were surprising initially, further evaluation may be able to clarify these findings. In order to receive a diagnosis of PDD-NOS, individuals are not required to have repetitive or stereotyped patterns of behavior (APA, 2000). Given that such behaviors are likely to fall within the stereotypies and self-injurious behaviors subscales (Iwata et al., 1994; Lovaas, Newsom, \& Hickman, 1987; Rapp \& Vollmer, 2005; Vollmer, 1994), the absence of this requirement may explain the lack of significant difference between PDD-NOS and atypically developing without an ASD diagnosis in relation to these specific challenging behaviors.

Although significant differences in endorsement rates of challenging behaviors between the autism and atypically developing without an ASD diagnosis group were not a core hypothesis of the present study, the aforementioned hypotheses placing autism, PDD-NOS, and atypically developing without an ASD diagnosis in a predicted order also implies this hypothesis. Results show that for all but one of the challenging behaviors there were significant differences in endorsement rates between the autism and atypically developing without an ASD diagnosis groups. The exception to this finding was the challenging behavior item of playing with own saliva. Since there were no significant differences with respect to this single challenging behavior, it may be that saliva play is consistent across groups. This would appear appropriate since saliva play is also commonly 
seen in typically developing infants and toddlers. Despite this one inconsistency, the remainder of the findings that individuals with autism significantly differ from those with atypical development without an ASD is in line with the current literature showing that individuals with ASD engage in more challenging behaviors than those with ID or those who are typically developing (Baghdadli et al., 2003; Holden \& Gitlesen, 2006; MacDonald et al., 2007; Matson, Wilkins, \& Macken, 2009).

Taken together, in regards to specific challenging behavior items, approximately half of the items were significantly different between the three diagnostic groups in the expected direction. For these items, the autism group had higher endorsements than the PDD-NOS group, who in turn had higher endorsements than the atypically developing without an ASD diagnosis group. Therefore, the problem behavior items that appear to best differentiate between autism, PDD-NOS, and atypical development without an ASD are kicking objects, throwing objects at others, banging on objects with hand, leaving the supervision of caregiver without permission, aggression toward others, property destruction, and repeated and unusual vocalizations. All of these items, with the exception of repeated and unusual vocalizations, are found within the aggressive/destructive behaviors subscale. This is interesting to note since aggressive/destructive behaviors are the only challenging behaviors assessed herein that are not at all integrated into DSM-IV-TR ASD diagnostic criteria, yet they are the only topography of challenging behavior to differentiate between specific ASD diagnoses and atypical development.

Although not all of the specific challenging behavior items were significantly different between the three diagnostic groups, further analysis and trend graphs revealed that the observed trend for each of the problem behavior items was that which had been predicted. Each behavior followed the trend of the autism group having higher endorsement than the PDD-NOS group who had higher endorsement than the atypically developing without an ASD group. Although not all of these differences were significant, all 15 challenging behaviors following the same trend is greater than would be expected by chance.

In further support of this study's hypotheses were the significant differences found between each of the three diagnostic groups when examining total endorsement of challenging behaviors. As was predicted, the 
autism group had significantly more challenging behavior endorsements than the PDD-NOS group who had significantly more than the atypically developing without an ASD diagnosis group. The reasoning for why overall problem behavior endorsement may be significantly different between groups while not all specific problem behavior endorsements were may be attributable to the functions of different behaviors. As was discussed earlier, there may be a variety of reasons why individuals with ASD and other disabilities engage in challenging behaviors. However, the topography of a specific challenging behavior may not effectively fulfill a desired function. For example, although aggression toward others may be effective in gaining access to tangibles, escaping from others, or receiving attention, it may not be as efficient in satisfying a non-social function. Yet, this does not necessarily mean that this individual will not engage in more challenging behaviors than someone else. It merely helps decide which specific challenging behaviors may be more likely to occur.

The hypotheses regarding gender differences among challenging behavior items received modest support through the results of this study. As was expected, there were no significant differences between males and females in endorsement rates of stereotypic behaviors or self-injurious behaviors, nor were there any interactions of diagnostic group and gender in relation to these behaviors. These results are identical to those that had been found by previous researchers who also noted no significant differences between genders in relation to stereotypic behaviors within typically developing populations (Harris et al., 2008) and self-injurious behaviors within ID populations (Holden \& Gitlesen, 2006; Lowe et al., 2007; McClintock et al., 2003). However, there were also no significant differences between males and females in endorsement rates of aggressive/destructive behaviors. In conjunction with this, there were also no interactions of diagnostic group and gender for these behaviors. These findings had been somewhat unexpected since prior research has found that males with ASDs evince greater rates of aggressive/destructive behaviors than females with ASDs (McClintock et al., 2003). Additionally, similar differences between males and females with respect to aggressive/destructive behaviors had previously been found in typically developing individuals (Alink et al., 2006; Lee et al., 2007) as well as in individuals with ID (McClintock et al., 2003; Tyrer et al., 2006). However, there have been other studies comparing genders with respect to aggressive behavior that have found no 
significant differences, both among the ASD population (Murphy et al., 2009) and the ID population

(Hemmings et al., 2006; Tenneij \& Koot, 2008). As such, the findings of this study corroborate the latter findings. It appears that the presence of an ASD eliminates the effect of gender differences with regard to aggressive behaviors, perhaps due to the overall significantly greater prevalence of aggressive behaviors within this population.

However, one possible limitation to the finding of no significant gender differences in relation to aggressive behaviors may be that the measure utilized within this study is not sensitive to gender differences. When the BISCUIT-Part 3 is administered, caregivers are instructed to rate each challenging behavior item to the degree that it has been a problem recently. However, given society's different expectations for males and females (Baillargeon et al., 2007), caregivers may be less apt to identify an aggressive/destructive behavior as a problem when it is present within a male since aggressive/destructive behavior is more common within males than females. In such cases, caregivers may be more likely to embrace the stereotype of males being more aggressive/destructive than females, and thus indicate that it is either not presently a problem or is less severe of a problem than it would be rated in a female. Nevertheless, the current results are consistent with some previous findings thereby indicating that gender differences do not appear to exist in relation to this set of challenging behaviors among those with ASD.

One potential limitation to the current study is that ID was not taken into consideration. Previous research has found that the severity of ID severely impacts the occurrence of challenging behaviors (Allen, 2000; McClintock et al., 2003; Oliver et al., 1987; Rojahn et al., 2008; Tyrer et al., 2006). Due to the common comorbidity of ASD and ID (Fombonne, 2005; La Malfa, Lassi, Bertelli, Salvini, \& Placidi, 2004; Matson \& Shoemaker, 2009), the presence of ID within this study could be worthy of note. However, given the young cohort assessed, accurate assessment of intellectual functioning was not possible. Although assessment of developmental quotient was feasible, the Battelle Developmental Inventory, Second Edition (Newborg, 2005) is a recently revised measure that has not yet been researched with respect to its ability to predict future intellectual quotient, thus limiting its utility as a measure of ID. Furthermore, inclusion of developmental 
quotient as an independent variable would have severely restricted the available sample size due to the unavailability of exact scores from the Battelle Developmental Inventory, Second Edition to this author, thus infringing on maintaining an appropriate sample size as decided by an a priori power analysis for the analyses that had been proposed. Given that the focus of this manuscript was to detect significant differences in challenging behaviors with respect to Autistic Disorder versus PDD-NOS as well as those related to gender effects, it was decided that reducing the sample size would impede the ability to accurately find these differences thus deterring from the study's focus. Therefore, although the effects of developmental quotient and/or intellectual quotient may certainly affect challenging behaviors when co-morbid with either Autistic Disorder or PDD-NOS, this question should be addressed in future studies.

The results of the present study have many important implications. Although to a varying degree among different challenging behavior items, it may be possible to provide further assistance in differential diagnosis between autism and PDD-NOS by corroborating diagnostic criteria with endorsement rates of challenging behaviors. This is especially true when examining the total endorsement rate of challenging behaviors as a whole. Furthermore, given the glaring consequences of the presence of challenging behaviors for both genders, it is imperative to identify these behaviors as soon as they emerge so that interventions can be implemented to decrease their presence. It is apparent that significant differences in the endorsement rates of challenging behaviors are evident within the first few years of life, thus suggesting that these behaviors may further impede the success of individuals affected. Since challenging behaviors greatly affect learning opportunities (Emerson et al., 2000; Mudford et al., 2008), those individuals with autism may be at an even greater disadvantage than those with PDD-NOS given their greater likelihood of engaging in challenging behaviors. Additionally, due to the support from this study that severity of ASD, when considering PDD-NOS to be a less severe form of autism, is correlated with greater endorsements of challenging behaviors, future research may aim to identify the relationship between challenging behaviors and specific ASD diagnostic criteria. Knowledge of this kind would supply service providers with more individualized teaching strategies and other specific interventions. 


\section{References}

Alink, L. R. A., Mesman, J., van Zeijl, J., Stolk, M. N., Juffer, F., Koot, H. M., ... van IJzendoorn, M. H. (2006). The early childhood aggression curve: Development of physical aggression in 10- to 50-monthold children. Child Development, 77, 954-966.

Allen, D. (2000). Recent research on physical aggression in persons with intellectual disability: An overview. Journal of Intellectual and Developmental Disability, 25, 41-57.

Aman, M. G., Richmond, G., Stewart, A. W., Bell, J. C., \& Kissel, R. C. (1987). The Aberrant Behavior Checklist: Factor structure and the effect of subject variables in American and New Zealand facilities. American Journal of Mental Deficiency, 91, 570-578.

Aman, M. G., Singh, N. N., Stewart, A. W., \& Field, C. J. (1985a). The Aberrant Behavior Checklist: A behavior rating scale for the assessment of treatment effects. American Journal of Mental Deficiency, $89,485-491$.

Aman, M. G., Singh, N. N., Stewart, A. W., \& Field, C. J. (1985b). Psychometric characteristics of the Aberrant Behavior Checklist. American Journal of Mental Deficiency, 89, 492-502.

Aman, M. G., Tassé, M. J., Rojahn, J., \& Hammer, D. (1996). The Nisonger CBRF: A child behavior rating form for children with developmental disabilities. Research in Developmental Disabilities, 17, 41-57.

American Psychiatric Association (1980). Diagnostic and statistical manual of mental disorders ( $3^{\text {rd }}$ ed.). Washington, DC: Author.

American Psychiatric Association (1987). Diagnostic and statistical manual of mental disorders ( $3^{\text {rd }}$ ed. revised). Washington, DC: Author.

American Psychiatric Association (1994). Diagnostic and statistical manual of mental disorders (4 ${ }^{\text {th }}$ ed.). Washington, DC: Author.

American Psychiatric Association (2000). Diagnostic and statistical manual of mental disorders $\left(4^{\text {th }}\right.$ ed. - text revision). Washington, DC: Author.

Amir, R. E., Van den Veyver, I. B., Wan, M., Tran, C. Q., Francke, U., \& Zoghbi, H. Y. (1999). Rett syndrome is caused by mutations in X-linked MECP2, encoding methyl-CpG-binding protein 2. Nature Genetics, $23,185-188$.

Asperger, H. (1991). 'Autistic psychopathy' in childhood (U. Frith, Trans.). In U. Frith (Ed.), Autism and Asperger syndrome. New York: Cambridge University Press.

Baghdadli, A., Pascal, C., Grisi, S., \& Aussilloux, C. (2003). Risk factors for self-injurious behaviours among 222 young children with autistic disorders. Journal of Intellectual Disability Research, 47, 622-627.

Baillargeon, R. H., Zoccolillo, M., Keenan, K., Côté, S., Pérusse, D., Wu, H.-X., ... Tremblay, R. E. (2007). Gender differences in physical aggression: A prospective population-based survey of children before and after 2 years of age. Developmental Psychology, 43, 13-26.

Bleuler, E. (1913). Autistic thinking. American Journal of Insanity, 69, 873-886. 
Bodfish, J. W., Symons, F. J., Parker, D. E., \& Lewis, M. H. (2000). Varieties of repetitive behavior in autism: Comparisons to mental retardation. Journal of Autism and Developmental Disorders, 30, 237-243.

Brinkley, J., Nations, L., Abramson, R. K., Hall, A., Wright, H. H., Gabriels, R., .. Cuccaro, M. L. (2007). Factor analysis of the Aberrant Behavior Checklist in individuals with autism spectrum disorders. Journal of Autism and Developmental Disorders, 37, 1949-1959.

Brown, E. C., Aman, M. G., \& Havercamp, S. M. (2002). Factor analysis and norms for parent ratings on the Aberrant Behavior Checklist-Community for young people in special education. Research in Developmental Disabilities, 23, 45-60.

Buitelaar, J. K., Van der Gaag, R., Klin, A., \& Volkmar, F. (1999). Exploring the boundaries of pervasive developmental disorder not otherwise specified: Analyses of data from the DSM-IV autistic disorder field trial. Journal of Autism and Developmental Disorders, 29, 33-43.

Calloway, C. J., \& Simpson, R. L. (1998). Decisions regarding functions of behavior: Scientific versus informal analyses. Focus on Autism and Other Developmental Disabilities, 13, 167-175.

Carcani-Rathwell, I., Rabe-Hasketh, S., \& Santosh, P. J. (2006). Repetitive and stereotyped behaviours in pervasive developmental disorders. Journal of Child Psychology and Psychiatry, 47, 573-581.

Carey, T., Ratliff-Schaub, K., Funk, J., Weinle, C., Myers, M., \& Jenks, J. (2002). Double-blind placebocontrolled trial of secretin: Effects on aberrant behavior in children with autism. Journal of Autism and Developmental Disorders, 32, 161-167.

Carlyle, K. E., \& Steinman, K. J. (2007). Demographic differences in the prevalence, co-occurrence, and correlates of adolescent bullying at school. Journal of School Health, 77, 623-629.

Chahrour, M., \& Zoghbi, H. Y. (2007). The story of Rett syndrome: From clinic to neurobiology. Neuron, 56, 422-437.

Chakrabarti, S., \& Fombonne, E. (2001). Pervasive developmental disorders in preschool children. Journal of the American Medical Association, 285, 3093-3099.

Chakrabarti, S., \& Fombonne, E. (2005). Pervasive developmental disorders in preschool children: Confirmation of high prevalence. American Journal of Psychiatry, 162, 1133-1141.

Cohen, I. L. (2003). Criterion-related validity of the PDD Behavior Inventory. Journal of Autism and Developmental Disorders, 33, 47-53.

Cohen, I. L., Schmidt-Lackner, S., Romanczyk, R., \& Sudhalter, V. (2003). The PDD Behavior Inventory: A rating scale for assessing response to intervention in children with pervasive developmental disorder. Journal of Autism and Developmental Disorders, 33, 31-45.

Cohen, J. (1992). A power primer. Psychological Bulletin, 112, 155-159.

Cohen, J. (1988). Statistical power analysis for the behavioral sciences (2nd ed.). Hillsdale, NJ: Lawrence Earlbaum Associates. 
Crocker, A. G., Mercier, C., Lachapelle, Y., Brunet, A., Morin, D., \& Roy, M.-E. (2006). Prevalence and types of aggressive behaviour among adults with intellectual disabilities. Journal of Intellectual Disability Research, 50, 652-661.

Cuccaro, M. L., Nations, L., Brinkley, J., Abramson, R. K., Wright, H. H., Hall, A., ... Pericak-Vance, M. A. (2007). A comparison of repetitive behaviors in Aspergers disorder and high functioning autism. Child Psychiatry and Human Development, 37, 347-360.

Dodge, K., \& Coie, J. (1987). Social-information-processing factors in reactive and proactive aggression in children's peer groups. Journal of Personality and Social Psychology, 53, 1146-1158.

Dominick, K. C., Ornstein Davis, N., Lainhart, J., Tager-Flusberg, H., \& Folstein, S. (2007). Atypical behaviors in children with autism and children with history of language impairment. Research in Developmental Disabilities, 28, 145-162.

Durand, V. M., \& Crimmins, D. B. (1988). Identifying the variables maintaining self-injurious behavior. Journal of Autism and Developmental Disorders, 18, 99-117.

Eisenberg, L. (1956). The autistic child in adolescence. American Journal of Psychiatry, 112, 607-612.

Emerson, E. (2005). Challenging behaviour: Analysis and intervention with people with learning difficulties. Cambridge: Cambridge University Press.

Emerson, E., Kiernan, C., Alborz, A., Reeves, D., Mason, H., Swarbrick, R., ... Hatton, C. (2001). The prevalence of challenging behaviors: A total population study. Research in Developmental Disabilities, $22,77-93$.

Emerson, E., Robertson, J., Gregory, N., Hatton, C., Kessissoglou, S., Hallam, A., \& Hillery, J. (2000). Treatment and management of challenging behaviors in residential settings. Journal of Applied Research in Intellectual Disabilities, 13, 197-215.

Eveloff, H. (1960). The autistic child. Archives of General Psychiatry, 3, 66-81.

Farmer, C. A., \& Aman, M. G. (2009). Development of the Children's Scale of Hostility and Aggression: Reactive/Proactive (C-SHARP). Research in Developmental Disabilities, 30, 1155-1167.

Fatemi, S. H., Realmuto, G. M., Khan, L., \& Thuras, P. (1998). Fluoxetine in treatment of adolescent patients with autism: A longitudinal open trial. Journal of Autism and Developmental Disorders, 28, 303-307.

Faul, F., Erdfelder, E., Lang, A.-G., \& Buchner, A. (2007). G*Power 3: A flexible statistical power analysis program for the social, behavioral, and biomedical sciences. Behavior Research Methods, 39, 175-191.

Field, A. (2005). Discovering statistics using SPSS (2nd ed.). London: Sage Publications.

Fombonne, E. (2005). The changing epidemiology of autism. Journal of Applied Research in Intellectual Disabilities, 18, 281-294.

Gabriels, R. L., Cuccaro, M. L., Hill, D. E., Ivers, B. J., \& Goldson, E. (2005). Repetitive behaviors in autism: Relationships with associated clinical features. Research in Developmental Disabilities, 26, 169-181. 
Glass, G. V., Peckham, P. D., \& Sanders, J. R. (1972). Consequences of failure to meet assumptions underlying analysis of variance and covariance. Review of Educational Research, 42, 237-288.

Goldman, S., Wang, C., Salgado, M. W., Greene, P. E., Kim, M., \& Rapin, I. (2009). Motor stereotypies in children with autism and other developmental disorders. Developmental Medicine and Child Neurology, $51,30-38$.

Green, V. A., O'Reilly, M., Itchon, J., \& Sigafoos, J. (2005). Persistence of early emerging aberrant behavior in children with developmental disabilities. Research in Developmental Disabilities, 26, 47-55.

Harris, K. M., Mahone, E. M., \& Singer, H. S. (2008). Nonautistic motor stereotypies: Clinical features and longitudinal follow-up. Pediatric Neurology, 38, 267-272.

Hartley, S. L., Sikora, D. M., \& McCoy, R. (2008). Prevalence and risk factors of maladaptive behaviour in young children with autistic disorder. Journal of Intellectual Disability Research, 52, 819-829.

Harwell, M. R., Rubinstein, E. N., Hayes, W. S., \& Olds, C. C. (1992). Summarizing Monte Carlo results in methodological research: The one- and two-factor fixed effects ANOVA cases. Journal of Educational Statistics, 17, 315-339.

Hemmings, C. P., Gravestock, S., Pickard, M., \& Bouras, N. (2006). Psychiatric symptoms and problem behaviours in people with intellectual disabilities. Journal of Intellectual Disability Research, 50, 269276.

Hendry, C. N. (2000). Childhood disintegrative disorder: Should it be considered a distinct diagnosis? Clinical Psychology Review, 20, 77-90.

Herbert, J. D., Sharp, I. R., \& Gaudiano, B. A. (2002). Separating fact from fiction in the etiology and treatment of autism: A scientific review of the evidence. The Scientific Review of Mental Health Practice, 1, 2343.

Hinkle, D. E., Wiersma, W., \& Jurs, S. G. (2003). Applied statistics for the behavioral sciences. Boston: Houghton Mifflin Company.

Holden, B., \& Gitlesen, J. P. (2006). A total population study of challenging behaviour in the county of Hedmark, Norway: Prevalence, and risk markers. Research in Developmental Disabilities, 27, 456-465.

Howlin, P. (2006). Autism spectrum disorders. Psychiatry, 5, 320-324.

Iwata, B. A., Dorsey, M. F., Slifer, K. J., Bauman, K. E., \& Richman, G. S. (1982). Toward a functional analysis of self-injury. Analysis and Intervention in Developmental Disabilities, 2, 3-20.

Iwata, B. A., Pace, G. M., Dorsey, M. F., Zarcone, J. R., Vollmer, T. R., Smith, R. G., ... Willis, K. D. (1994). The functions of self-injurious behavior: An experimental-epidemiological analysis. Journal of Applied Behavior Analysis, 27, 215-240.

Kanner, L. (1943). Autistic disturbances of affective contact. The Nervous Child, 2, 217-250.

Kanner, L. (1944). Early infantile autism. Journal of Pediatrics, 25, 211-217. 
Kanner, L. (1951). The conception of wholes and parts in early infantile autism. American Journal of Psychiatry, 108, 23-26.

Kanner, L. (1965). Infantile autism and the schizophrenias. Behavioral Science, 10, 412-420.

Kanner, L. (1971). Follow-up study of eleven autistic children originally reported in 1943. Journal of Autism and Developmental Disorders, 1, 119-145.

Kanner, L., \& Eisenberg, L. (1957). Early infantile autism, 1943-1955. Psychiatric Research Reports, 7, 55-65.

Klin, A., \& Volkmar, F. R. (1997). Asperger syndrome. In D. J. Cohen \& F. R. Volkmar (Eds.), Handbook of autism and pervasive developmental disorders (pp. 94-122). New York: Wiley \& Sons.

Kravitz, H., \& Boehm, J. J. (1971). Rhythmic habit patterns in infancy: Their sequence, age of onset, and frequency. Child Development, 42, 399-413.

La Malfa, G., Lassi, M., Bertelli, R., Salvini, R., \& Placidi, G. F. (2004). Autism and intellectual disability: A study of prevalence on a sample of the Italian population. Journal of Intellectual Disability Research, $48,262-267$.

Lecavalier, L., Aman, M. G., Hammer, D., Stoica, W., \& Mathews, G. L. (2004). Factor analysis of the Nisonger Child Behavior Rating Form in children with autism spectrum disorders. Journal of Autism and Developmental Disorders, 34, 709-721.

Lee, K.-H., Baillargeon, R. H., Vermunt, J. K., Wu, H.-X., \& Tremblay, R. E. (2007). Age differences in the prevalence of physical aggression among 5-11-year-old Canadian boys and girls. Aggressive Behavior, $33,26-37$.

Leech, N. L., Barrett, K. C., \& Morgan, G. A. (2008). SPSS for intermediate statistics: Use and interpretation $\left(3^{\text {rd }}\right.$ ed.). New York: Lawrence Erlbaum Associates.

Lehmann, E. L. (2006). Nonparametrics statistical methods based on ranks. New York: Springer Science and Business Media, LLC.

Lewis, M. H., \& Bodfish, J. W. (1998). Repetitive behavior disorders in autism. Mental Retardation and Developmental Disabilities Research Reviews, 4, 80-89.

Lewis, M. H., Yanimura, Y., Lee, L. W., \& Bodfish, J. W. (2007). Animal models of restricted reptitive behavior in autism. Behavioural Brain Research, 176, 66-74.

Lindsay, W. R., Allan, R., Parry, C., Macleod, F., Cottrell, J., Overend, H., \& Smith, A. H. W. (2004). Anger and aggression in people with intellectual disabilities: Treatment and follow-up of consecutive referrals and a waiting list comparison. Clinical Psychology and Psychotherapy, 11, 255-264.

Lix, L. M., Keselman, J. C., \& Keselman, H. J. (1996). Consequences of assumption violations revisited: A quantitative review of alternatives to the one-way analysis of variance $\mathrm{F}$ test. Review of Educational Research, 66, 579-619.

Loftin, R. L., Odom, S. L., \& Lantz, J. F. (2008). Social interaction and repetitive motor behaviors. Journal of Autism and Developmental Disorders, 38, 1124-1135. 
Lord, C., \& Risi, S. (1998). Frameworks and methods in diagnosing autism spectrum disorders. Mental Retardation and Developmental Disabilities Research Reviews, 4, 90-96.

Lovaas, O. I., Newsom, C., \& Hickman, C. (1987). Self-stimulatory behavior and perceptual reinforcement. Journal of Applied Behavior Analysis, 20, 45-68.

Lowe, K., Allen, D., Jones, E., Brophy, S., Moore, K., \& James, W. (2007). Challenging behaviours: Prevalence and topographies. Journal of Intellectual Disability Research, 51, 625-636.

Luiselli, J. K., \& Slocumb, P. R. (1983). Management of multiple aggressive behaviors by differential reinforcement. Journal of Behavior Therapy and Experimental Psychiatry, 14, 343-347.

Lunney, G. H. (1970). Using analysis of variance with a dichotomous dependent variable: An empirical study. Journal of Educational Measurement, 7, 263-269.

MacDonald, R., Green, G., Mansfield, R., Geckeler, A., Gardenier, N., Anderson, J., ... Sanchez, J. (2007). Stereotypy in young children with autism and typically developing children. Research in Developmental Disabilities, 28, 266-277.

Martin, N. T., Gaffan, E. A., \& Williams, T. (1999). Experimental functional analyses for challenging behavior: A study of validity and reliability. Research in Developmental Disabilities, 20, 125-146.

Matson, J. L., Bamburg, J. W., Cherry, K. E., \& Paclawskyj, T. R. (1999). A validity study on the Questions About Behavioral Function (QABF) scale: Predicting treatment success for self-injury, aggression, and stereotypies. Research in Developmental Disabilities, 20, 163-176.

Matson, J. L., \& Boisjoli, J. A. (2007). Differential diagnosis of PDDNOS in children. Research in Autism Spectrum Disorders, 1, 75-84.

Matson, J. L., Boisjoli, J., Rojahn, J., \& Hess, J. (2009). A factor analysis of challenging behaviors assessed with the Baby and Infant Screen for Children with aUtIsm Traits (BISCUIT-Part 3). Research in Autism Spectrum Disorders, 3, 714-722.

Matson, J. L., \& Dempsey, T. (2008). Stereotypy in adults with autism spectrum disorders: Relationship and diagnostic fidelity. Journal of Developmental and Physical Disabilities, 20, 155-165.

Matson, J. L., Fodstad, J. C., \& Boisjoli, J. A. (2008). Nosology and diagnosis of Rett syndrome. Research in Autism Spectrum Disorders, 2, 601-611.

Matson, J. L., Fodstad, J. C., \& Rivet, T. T. (2009). The relationship of social skills and problem behaviors in adults with intellectual disability and autism or PDD-NOS. Research in Autism Spectrum Disorders, 3 , 258-268.

Matson, J. L., Gonzalez, M. L., \& Rivet, T. T. (2008). Reliability of the Autism Spectrum Disorder-Behavior Problems for Children (ASD-BPC). Research in Autism Spectrum Disorders, 2, 696-706.

Matson, J. L., Kuhn, D. E., Dixon, D. R., Mayville, S. B., Laud, R. B., Cooper, C. L., ... Matson, M. L. (2003). The development and factor structure of the Functional Assessment for multiple CausaliTy (FACT). Research in Developmental Disabilities, 24, 485-495. 
Matson, J. L., \& Mahan, S. (2009). Current status of research on childhood disintegrative disorder. Research in Autism Spectrum Disorders, 3, 861-867.

Matson, J. L., \& Minshawi, N. F. (2007). Functional assessment of challenging behavior: Toward a strategy for applied settings. Research in Developmental Disabilities, 28, 353-361.

Matson, J. L., \& Nebel-Schwalm, M. (2007). Assessing challenging behaviors in children with autism spectrum disorders: A review. Research in Developmental Disabilities, 28, 567-579.

Matson, J. L., \& Rivet, T. T. (2007). A validity study of the Autism Spectrum Disorders-Behavior Problems for Adults (ASD-BPA) scale. Journal of Developmental and Physical Disabilities, 19, 557-564.

Matson, J. L., \& Rivet, T. T. (2008). Reliability and factor structure of the Autism Spectrum Disorder-Behavior Problems for Adults (ASD-BPA) with intellectual disabilities. Journal of Mental Health Research in Intellectual Disabilities, 1, 34-47.

Matson, J. L., \& Shoemaker, M. (2009). Intellectual disability and its relationship to autism spectrum disorders. Research in Developmental Disabilities, 30, 1107-1114.

Matson, J. L., Wilkins, J., \& Macken, J. (2009). The relationship of challenging behaviors to severity and symptoms of autism spectrum disorders. Journal of Mental Health Research in Intellectual Disabilities, $2,29-44$.

Matson, J. L., Wilkins, J., Sevin, J. A., Knight, C., Boisjoli, J. A., \& Sharp, B. (2009). Reliability and item content of the Baby and Infant Screen for Children with aUtIsm Traits (BISCUIT): Parts 1-3. Research in Autism Spectrum Disorders, 3, 336-344.

Mayes, L., Volkmar, F., Hooks, M., \& Cicchetti, D. (1993). Differentiating pervasive developmental disorder not otherwise specified from autism and language disorders. Journal of Autism and Developmental Disorders, 23, 79-90.

McClintock, K., Hall, S., \& Oliver, C. (2003). Risk markers associated with challenging behaviours in people with intellectual disabilities: A meta-analytic study. Journal of Intellectual Disability Research, 47, 405416.

Montes, G., \& Halterman, J. S. (2007). Bullying among children with autism and the influence of comorbidity with ADHD: A population-based study. Ambulatory Pediatrics, 7, 253-257.

Mount, R. H., Hastings, R. P., Reilly, S., Cass, H., \& Charman, T. (2002). Behaviour problems in adult women with Rett syndrome. Journal of Intellectual Disability Research, 46, 619-624.

Mouridsen, S. E. (2003). Childhood disintegrative disorder. Brain and Development, 25, 225-228.

Mudford, O. C., Arnold-Saritepe, A. M., Phillips, K. J., Locke, J. M., Ho, I. C. S., \& Taylor, S. A. (2008). Challenging behaviors. In J. L. Matson (Ed.), Clinical assessment and intervention for autism spectrum disorders (pp. 267-297). London: Elsevier Inc.

Mukaddes, N. M., \& Topcu, Z. (2006). Case report: Homicide by a 10-year-old girl with autistic disorder. Journal of Autism and Developmental Disorders, 36, 471-474. 
Murphy, G., Hall, S., Oliver, C., \& Kissi-Debra, R. (1999). Identification of early self-injurious behavior in young children with intellectual disability. Journal of Intellectual Disability Research, 43, 149-163.

Murphy, O., Healy, O., \& Leader, G. (2009). Risk factors for challenging behaviors among 157 children with autism spectrum disorder in Ireland. Research in Autism Spectrum Disorders, 3, 474-482.

Nebel-Schwalm, M. S., \& Matson, J. L. (2008). Differential diagnosis. In J. L. Matson (Ed.), Clinical assessment and intervention for autism spectrum disorders (pp. 91-129). London: Elsevier, Inc.

Newborg, J. (2005). Battelle Developmental Inventory, Second Edition. Itasca: Riverside.

Nicholas, J. S., Charles, J. M., Carpenter, L. A., King, L. B., Jenner, W., \& Spratt, E. G. (2008). Prevalence and characteristics of children with autism-spectrum disorders. Annals of Epidemiology, 18, 130-136.

Nicholson, J., Konstantinidi, E., \& Furniss, F. (2006). On some psychometric properties of the Questions About Behavioral Function (QABF) scale. Research in Developmental Disabilities, 27, 337-352.

Oliver, C., Murphy, G. H., \& Corbett, J. A. (1987). Self-injurious behaviour in people with mental handicap: A total population study. Journal of Mental Deficiency Research, 31, 147-162.

Paclawskyj, T. R., Matson, J. L., Rush, K. S., Smalls, Y., \& Vollmer, T. R. (2000). Questions About Behavioral Function (QABF): A behavioral checklist for functional assessment of aberrant behavior. Research in Developmental Disabilities, 21, 223-229.

Rapp, J. T., \& Vollmer, T. R. (2005). Stereotypy I: A review of behavioral assessment and treatment. Research in Developmental Disabilities, 26, 527-547.

Richdale, A. L., \& Schreck, K. A. (2008). Assessment and intervention in autism: An historical perspective. In J. L. Matson (Ed.), Clinical assessment and intervention for autism spectrum disorders (pp. 3-32). London: Elsevier, Inc.

Robins, D. L., Fein, D., Barton, M. L., \& Green, J. A. (2001). The Modified Checklist for Autism in Toddlers: An initial study investigating the early detection of autism and pervasive developmental disorders. Journal of Autism and Developmental Disorders, 31, 131-144.

Rojahn, J., Aman, M. G., Matson, J. L., \& Mayville, E. (2003). The Aberrant Behavior Checklist and the Behavior Problems Inventory: Convergent and divergent validity. Research in Developmental Disabilities, 24, 391-404.

Rojahn, J., Matson, J. L., Lott, D., Esbensen, A. J., \& Smalls, Y. (2001). The Behavior Problems Inventory: An instrument for the assessment of self-injury, stereotyped behavior, and aggression/destruction in individuals with developmental disabilities. Journal of Autism and Developmental Disorders, 31, 577 588.

Rojahn, J., Matson, J. L., Mahan, S., Fodstad, J. C., Knight, C., Sevin, J. A., \& Sharp, B. (2009). Cutoffs, norms, and patterns of problem behaviors in children with ASD on the Baby and Infant Screen for Children with aUtIsm Traits (BISCUIT-Part 3). Research in Autism Spectrum Disorders, 3, 989-998. 
Rojahn, J., Schroeder, S. R., \& Hoch, T. A. (2008). Self-injurious behavior in intellectual disabilities. Amsterdam: Elsevier.

Rutter, M. (1972). Childhood schizophrenia reconsidered. Journal of Autism and Childhood Schizophrenia, 2, 315-337.

Rutter, M. (1978). Diagnosis and definition of childhood autism. Journal of Autism and Developmental Disorders, 8, 139-161.

Scarborough, A. A., \& Poon, K. K. (2004). The ecological context of challenging behavior in young children with developmental disabilities. International Review of Research in Mental Retardation, 29, 229-260.

Schroeder, S. R., Mulick, J. A., \& Rojahn, J. (1980). The definition, taxonomy, epidemiology, and ecology of self-injurious behavior. Journal of Autism and Developmental Disorders, 10, 417-432.

Sears, L. L., Vest, C., Mohamed, S., Bailey, J., Ranson, B. J., \& Piven, J. (1999). An MRI study of the basal ganglia in autism. Progress in Neuro-Psychopharmacology and Biological Psychiatry, 23, 613-624.

Sevin, B. M., Knight, C. L., \& Braud, S. A. (2007). Autism and pervasive developmental disorders. In J. L. Matson (Ed.), Handbook of assessment in persons with intellectual disability (pp. 163-195). London: Academic Press.

Sharma, N. (2009). Encyclopedia of Neuroscience (3rd ed.). San Diego: Elsevier.

Sigafoos, J., Kerr, M., \& Roberts, D. (1994). Interrater reliability of the motivation assessment scale: Failure to replicate with aggressive behavior. Research in Developmental Disabilities, 15, 333-342.

Singer, H. S. (2009). Motor stereotypies. Seminars in Pediatric Neurology, 16, 77-81.

Singh, N. N., Lancioni, G. E., Winton, A. S. W., Fisher, B. C., Wahler, R. G., McAleavey, K., et al. (2006). Mindful parenting decreases aggression, noncompliance, and self-injury in children with autism. Journal of Emotional and Behavioral Disorders, 14, 169-177.

Sturmey, P., Fink, C., \& Sevin, J. A. (1993). The Behavior Problem Inventory: A replication and extension of its psychometric properties. Journal of Developmental and Physical Disabilities, 5, 327-336.

Sturmey, P., Seiverling, L., \& Ward-Horner, J. (2008). Assessment of challenging behaviors in people with autism spectrum disorders. In J. L. Matson (Ed.), Clinical assessment and intervention for autism spectrum disorders (pp. 131-163). London: Elsevier, Inc.

Sturmey, P., Sevin, J. A., \& Williams, D. E. (1995). The Behavior Problem Inventory: A further replication of its factor structure. Journal of Intellectual Disability Research, 39, 353-356.

Tassé, M. J., Aman, M. G., Hammer, D., \& Rojahn, J. (1996). The Nisonger Child Behavior Rating Form: Age and gender effects and norms. Research in Developmental Disabilities, 17, 59-75.

Tate, B. G., \& Baroff, G. S. (1966). Aversive control of self-injurious behavior in a psychotic boy. Behavior Research and Therapy, 4, 281-287. 
Tenneij, N. H., \& Koot, H. M. (2008). Incidence, types and characteristics of aggressive behaviour in treatment facilities for adults with mild intellectual disability and severe challenging behaviour. Journal of Intellectual Disability Research, 52, 114-124.

Tidmarsh, L., \& Volkmar, F. R. (2003). Diagnosis and epidemiology of autism spectrum disorders. Canadian Journal of Psychiatry, 48, 517-525.

Toogood, S., \& Timlin, K. (1996). The functional assessment of challenging behaviour: A comparison of informant-based, experimental and descriptive methods. Journal of Applied Research in Intellectual Disabilities, 9, 206-222.

Tyrer, F., McGrother, C. W., Thorp, C. F., Donaldson, M., Bhaumik, S., Watson, J. M., Hollin, C. (2006). Physical aggression towards others in adults with learning disabilities: Prevalence and associated factors. Journal of Intellectual Disability Research, 50, 295-304.

Vollmer, T. R. (1994). The concept of automatic reinforcement: Implications for behavioral research in developmental disabilities. Research in Developmental Disabilities, 15, 187-207.

Willemsen-Swinkels, S. H. N., \& Buitelaar, J. K. (2002). The autistic spectrum: Subgroups, boundaries, and treatment. Psychiatric Clinics of North America, 25, 811-836.

Willemsen-Swinkels, S. H. N., Buitelaar, J. K., van Berckelaer-Onnes, I. A., \& van Engeland, H. (1999). Brief report: Six months continuation treatment in naltrexone-responsive children with autism: An open-label case-control design. Journal of Autism and Developmental Disorders, 29, 167-169.

Williams, K., Mellis, C., \& Peat, J. K. (2005). Incidence and prevalence of autism. Advances in SpeechLanguage Pathology, 7, 31-40.

Wing, L., \& Potter, D. (2002). The epidemiology of autistic spectrum disorders: Is the prevalence rising? Mental Retardation and Developmental Disabilities Research Reviews, 8, 151-161.

World Health Organization (1992). International classification of diseases $\left(10^{\text {th }}\right.$ ed.). Geneva, Switzerland: Author.

Zarcone, J. R., Rodgers, T. A., Iwata, B. A., Rourke, D. A., \& Dorsey, M. F. (1991). Reliability analysis of the motivation assessment scale: A failure to replicate. Research in Developmental Disabilities, 12, 349360. 


\section{Appendix A}

Items on the BISCUIT-Part 3:

Poking him/her self in the eye.

Harming self by hitting, pinching, scratching, etc.

Kicking objects (e.g., doors, walls).

Removal of clothing at inappropriate times.

Unusual play with objects (e.g., twirling string, staring at a toy, etc.).

Playing with own saliva.

Throwing objects at others.

Banging on objects (e.g. doors, walls, windows) with hand.

Leaving the supervision of caregiver without permission (i.e., elopement).

Aggression towards others.

Pulling others' hair.

Yelling or shouting at others.

Property destruction (e.g., ripping, breaking, tearing, crushing, etc.).

Repeated and unusual vocalizations (e.g., yelling, humming, etc.).

Repeated and unusual body movements (e.g., handflapping, waving arms, etc.). 


\section{Appendix B}

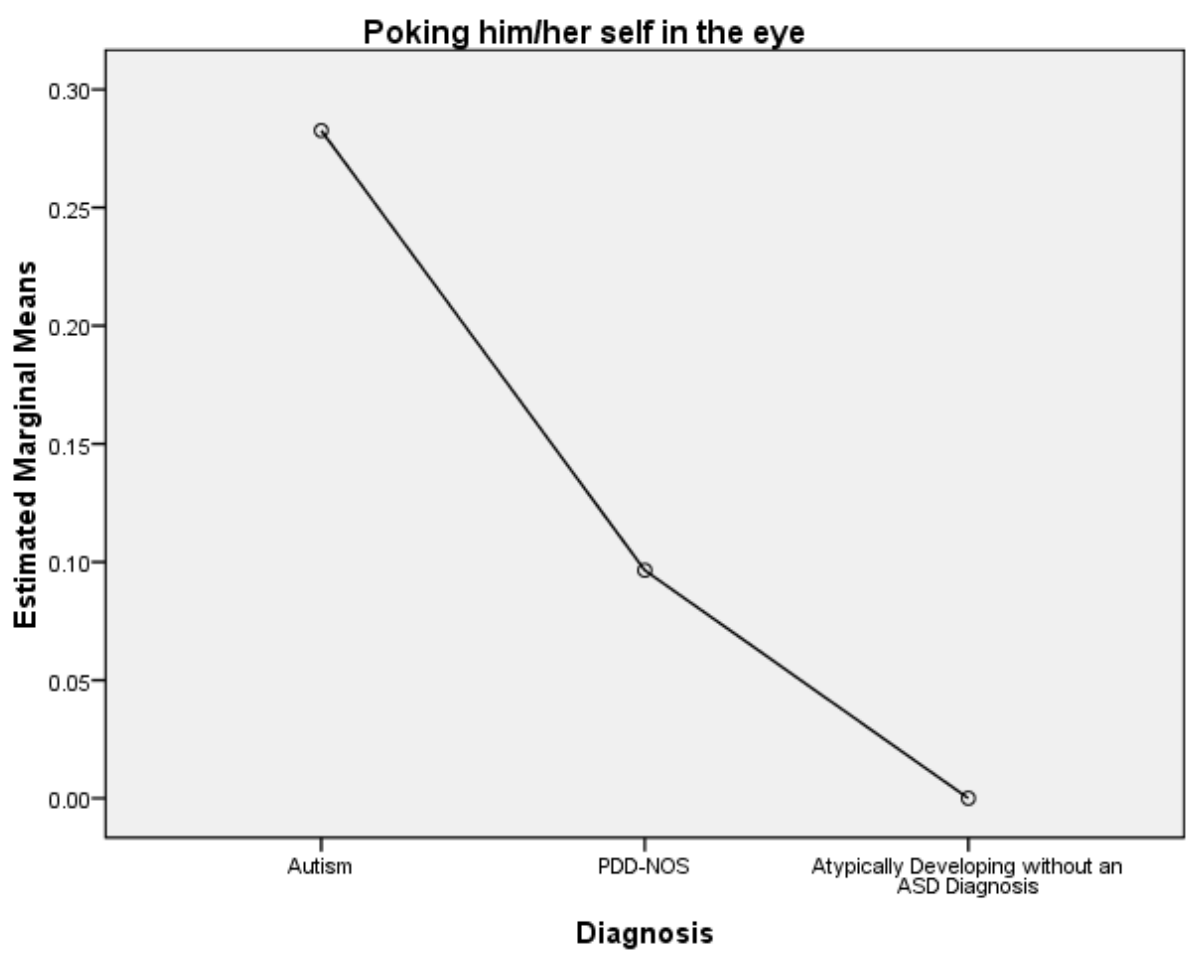

Harming self by hitting, pinching, scratching, etc.

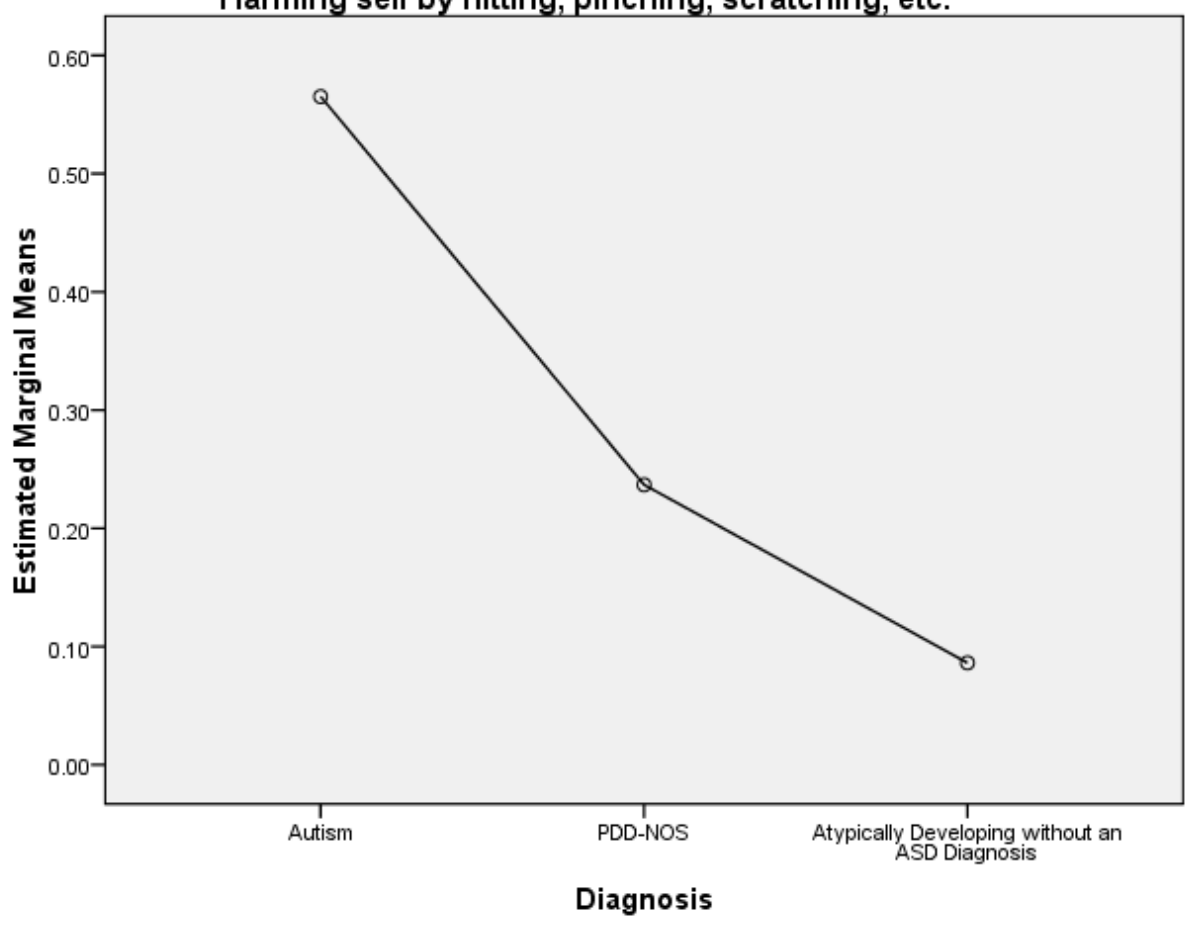




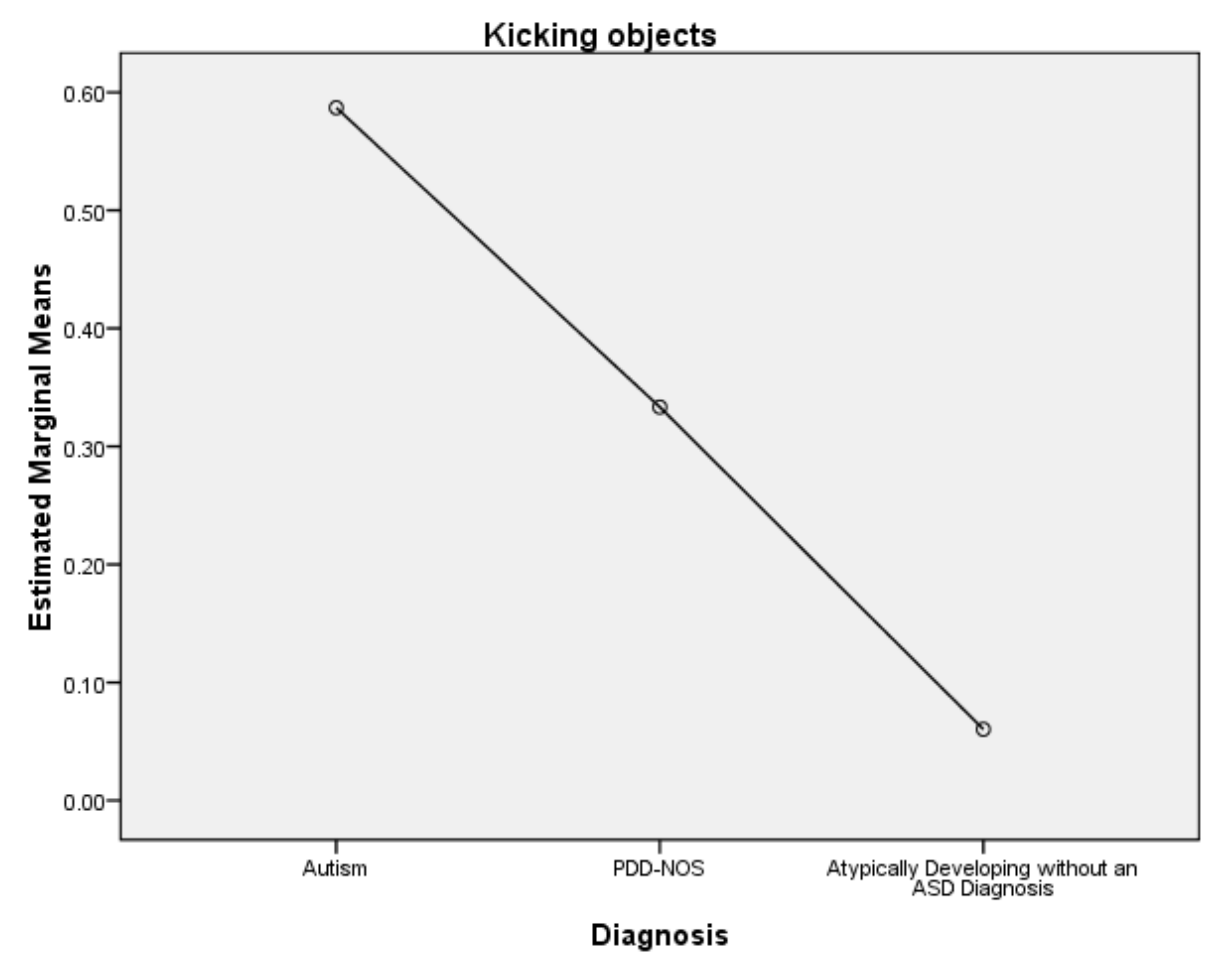

Removal of clothing at inappropriate times

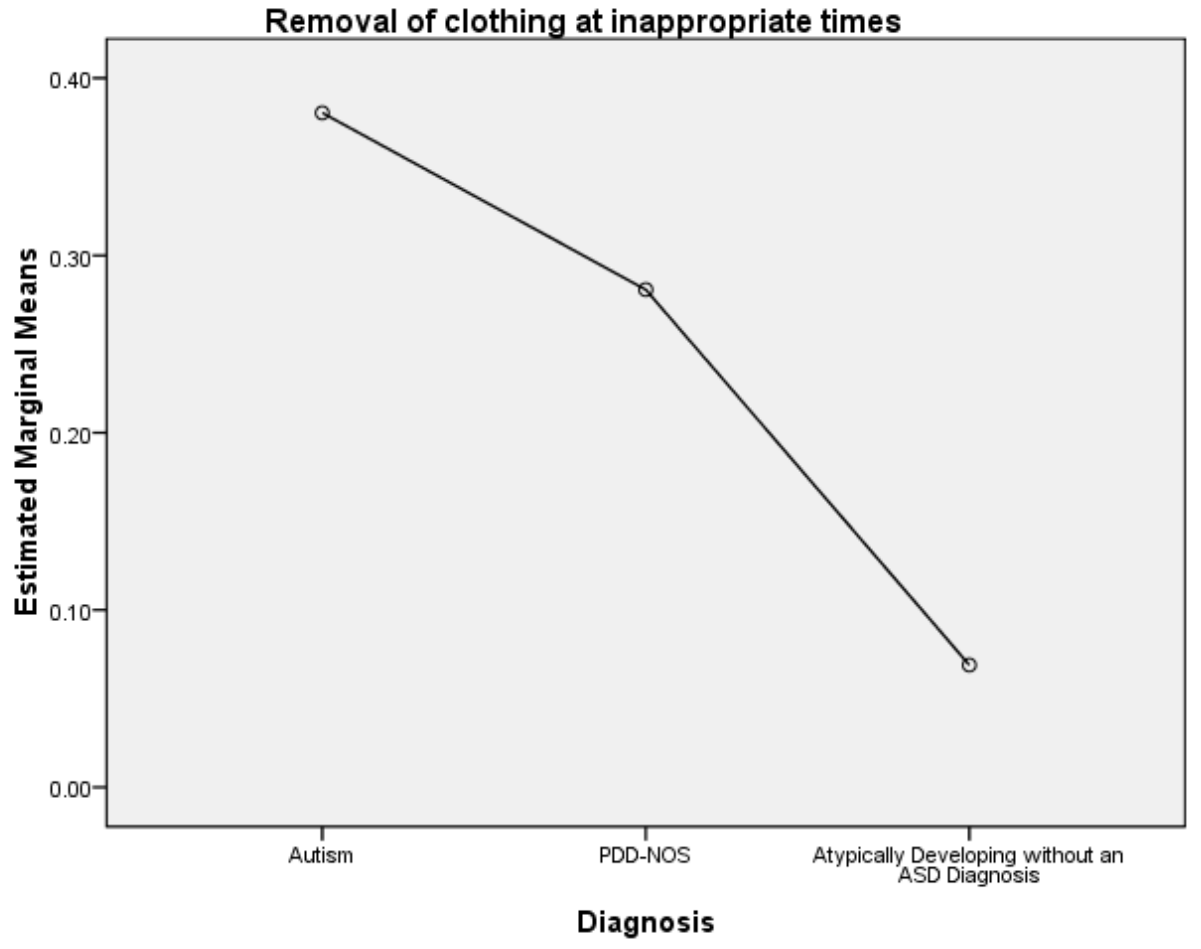



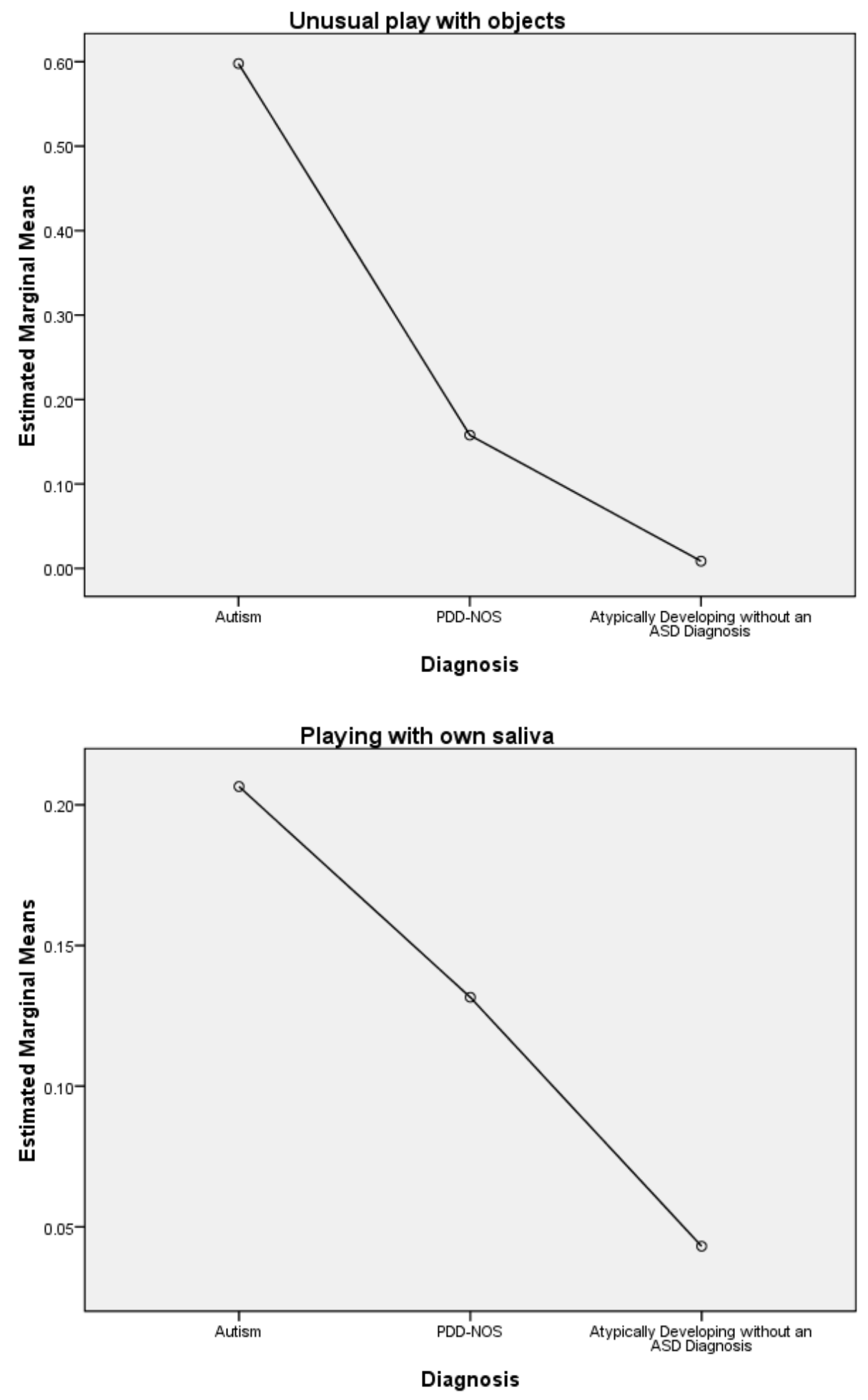
Throwing objects at others
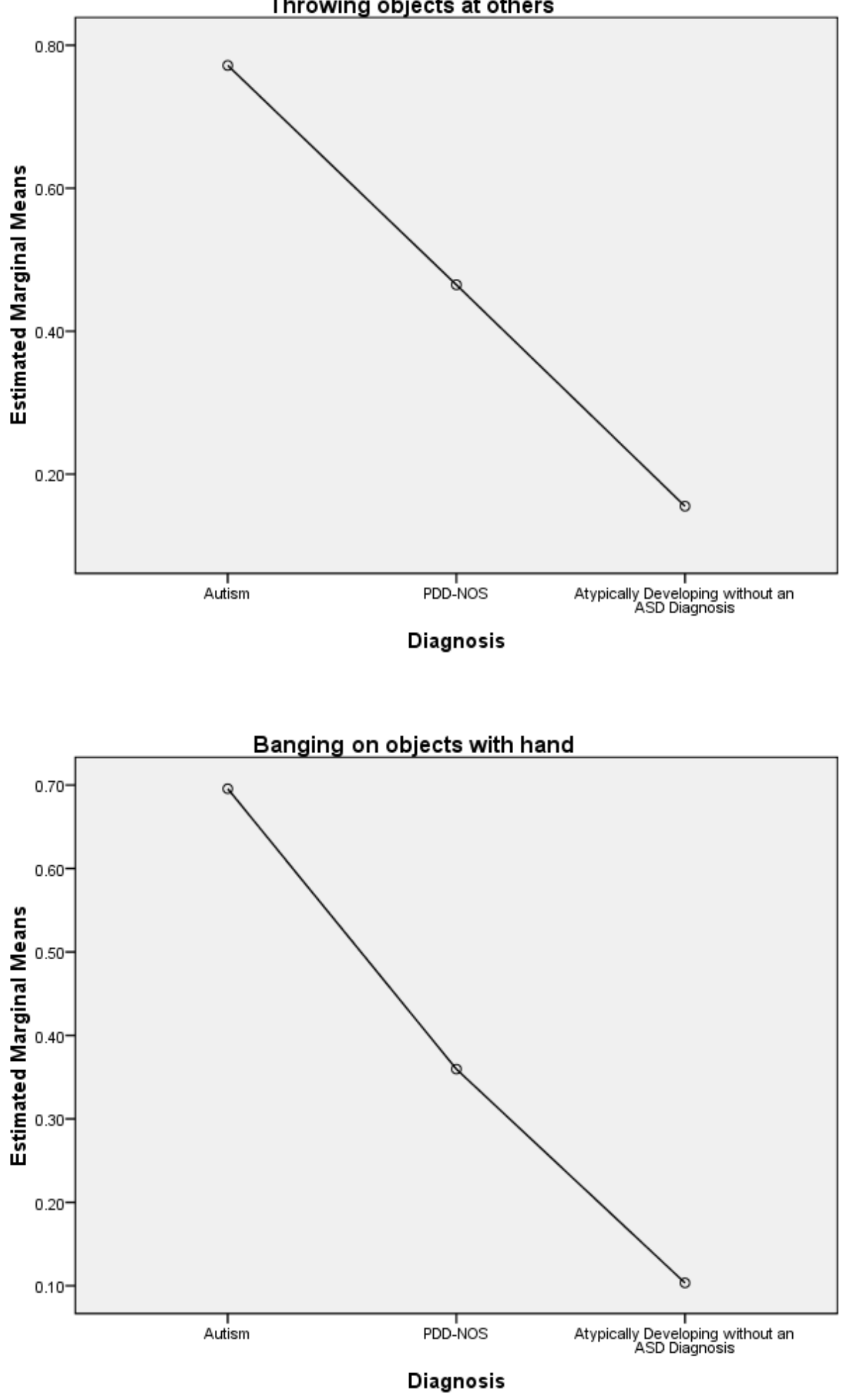

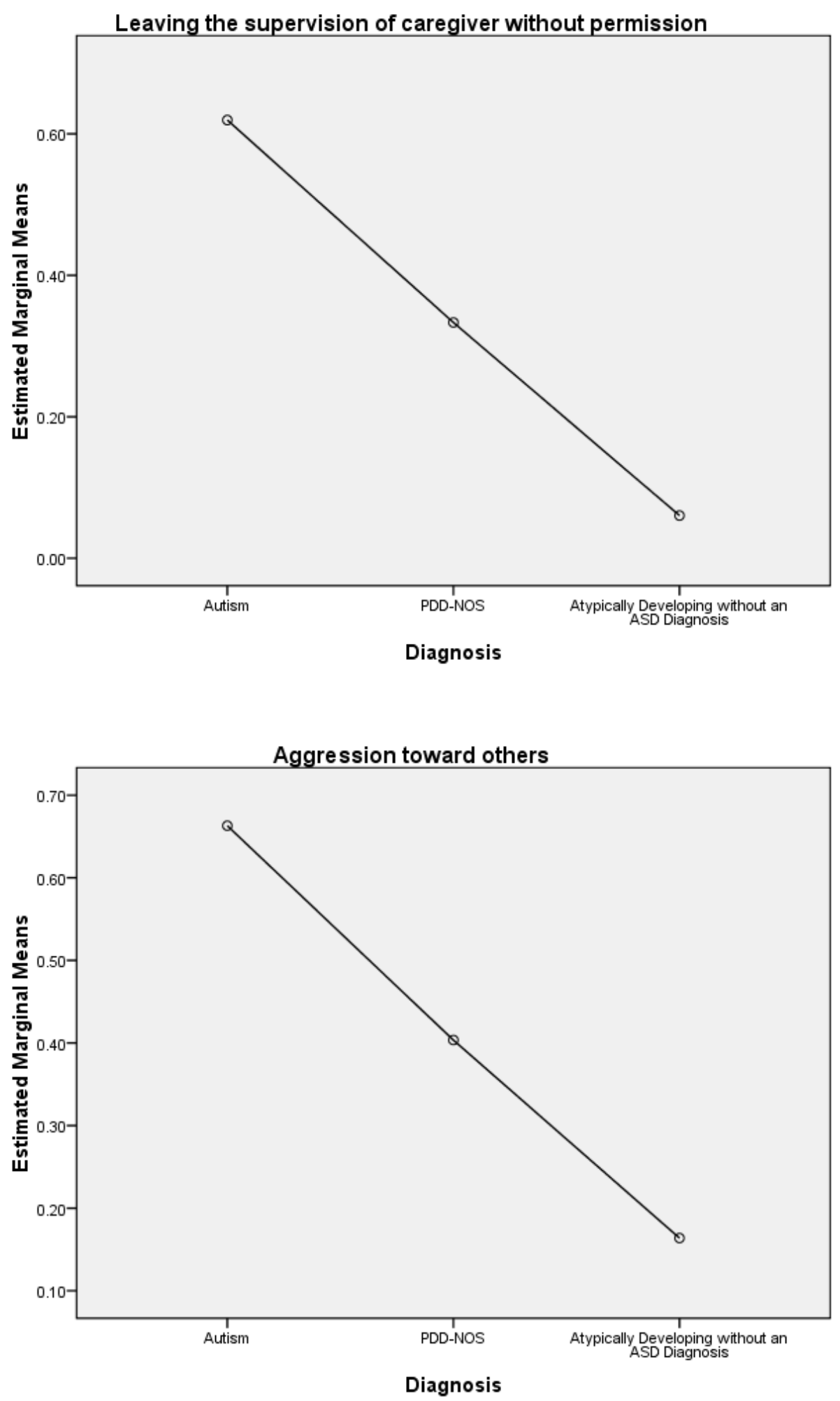

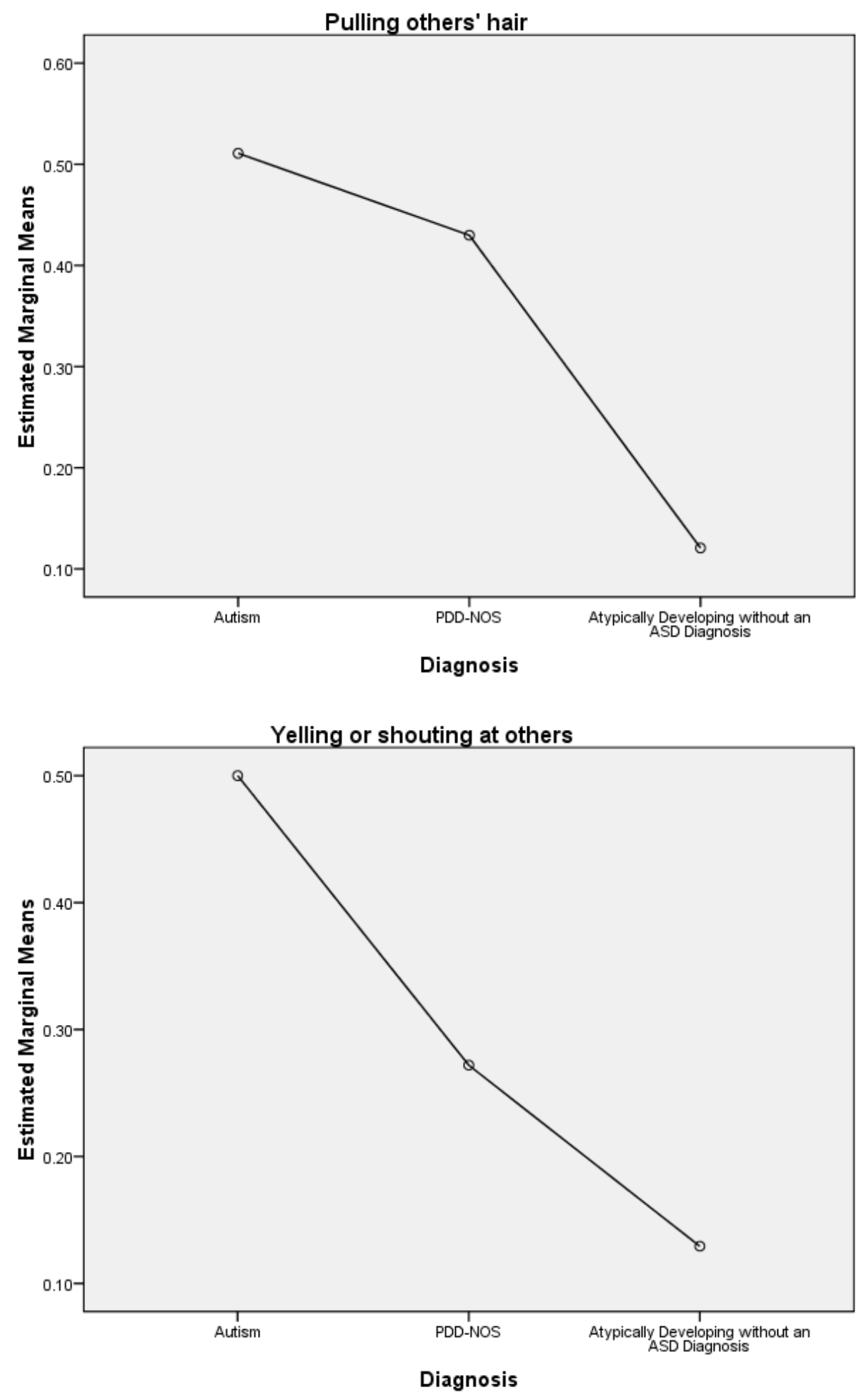

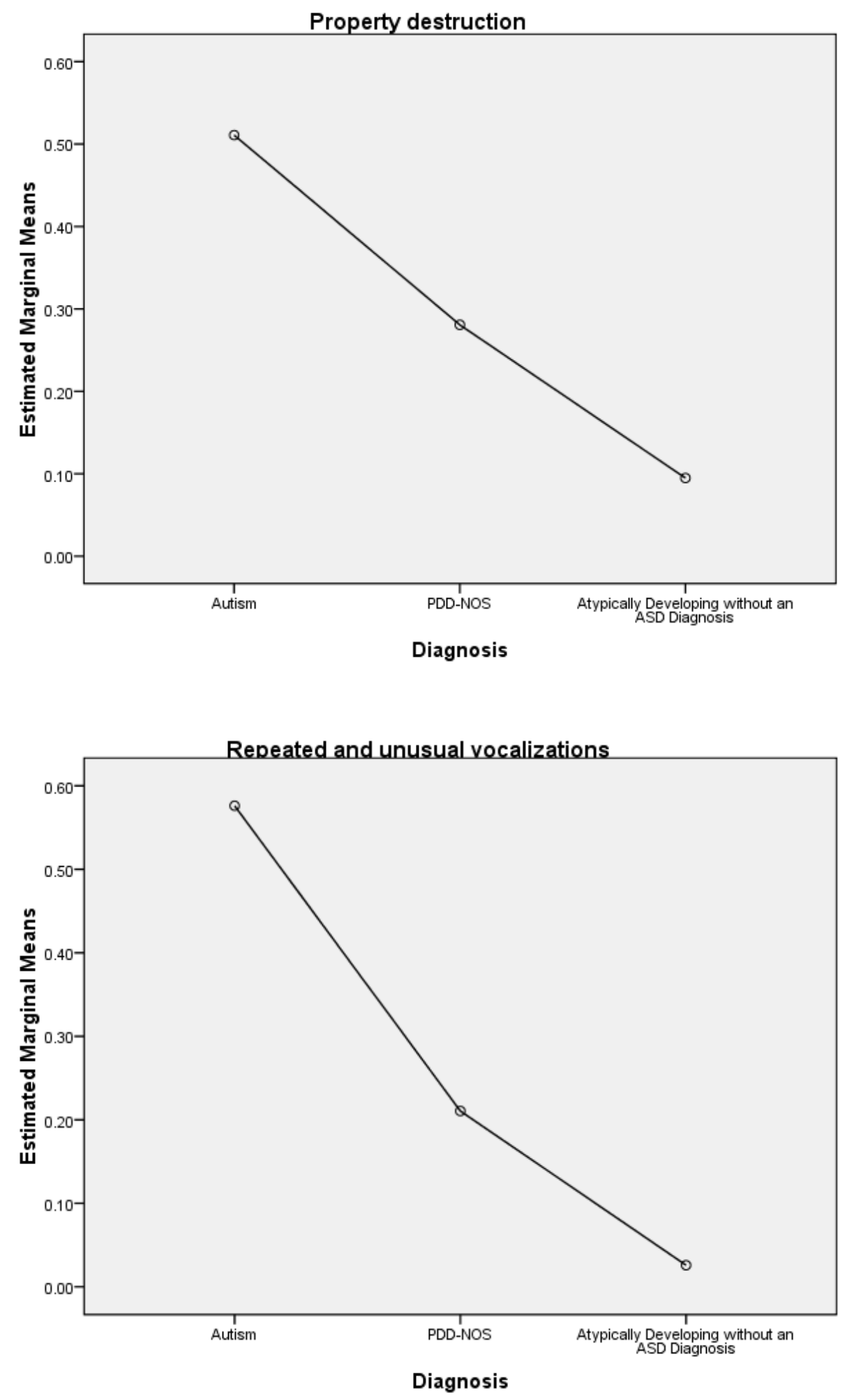


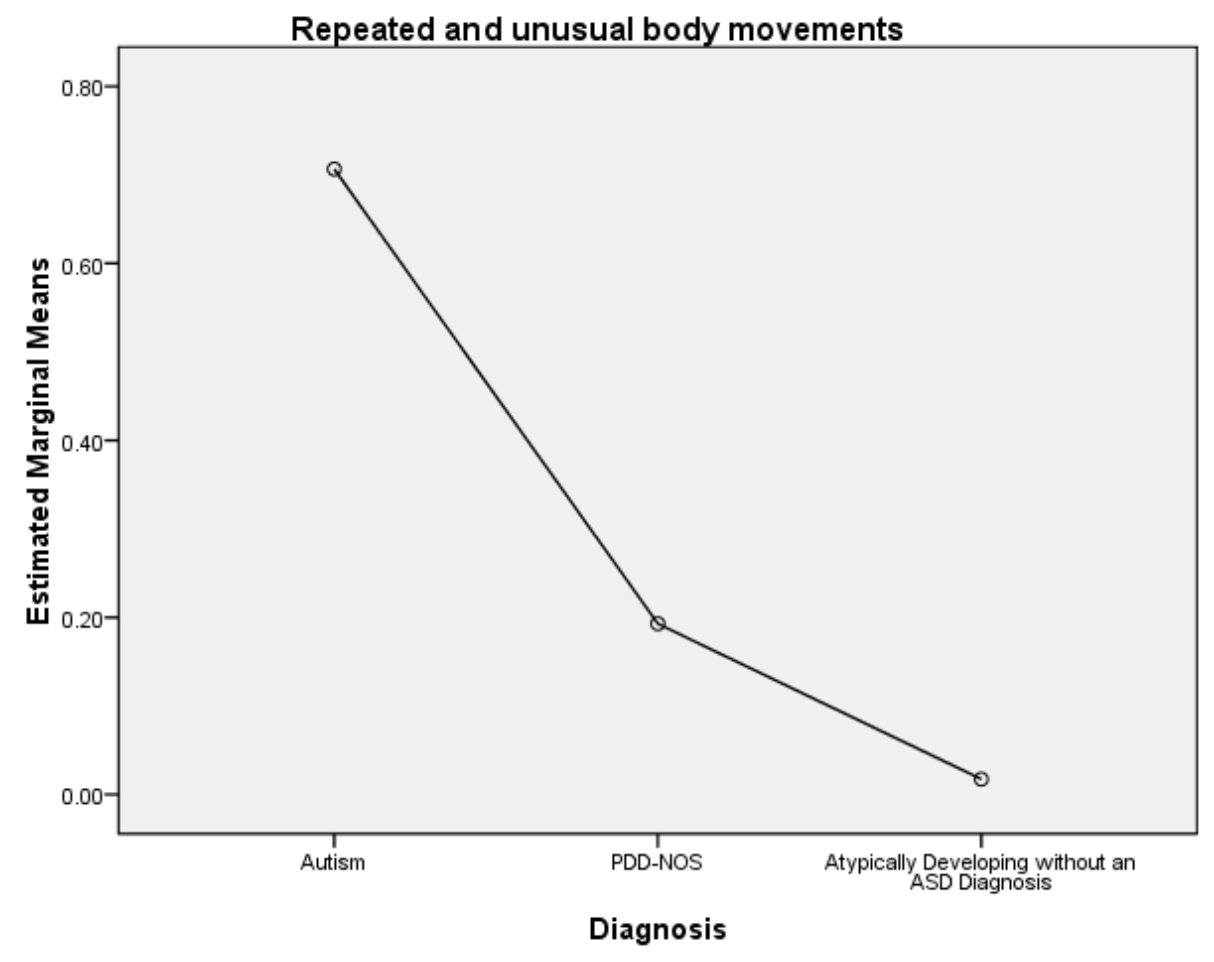




\section{Vita}

Alison M. Kozlowski was born in New Britain, Connecticut, in 1985. She received her Bachelor of Arts degree in psychology from Boston University in 2006. Following completion of her degree, she was employed at the May Institute in Randolph, Massachusetts, as the head teacher of a classroom for children with autism spectrum disorders. She subsequently enrolled in Louisiana State University's Clinical Psychology Doctoral Program in 2008. Her current clinical and research interests are the assessment and treatment of individuals with Autism Spectrum Disorders and other developmental disabilities, with a particular emphasis on challenging behaviors and communication training. 